OPEN ACCESS

Edited by:

Sara Pedron,

University of Illinois at UrbanaChampaign, United States

Reviewed by: Mark William Tibbitt,

ETH Zurich, Switzerland Jennifer Patterson, KU Leuven, Belgium April Kloxin, University of Delaware, United States

${ }^{*}$ Correspondence: Molly S. Shoichet molly.shoichet@utoronto.ca Co-first authors.

Specialty section: This article was submitted to Biomaterials,

a section of the journa Frontiers in Materials

Received: 15 December 2017 Accepted: 22 February 2018 Published: 12 March 2018

Citation:

Tuladhar A, Payne SL and Shoichet MS (2018) Harnessing the Potential of Biomaterials for Brain Repair after Stroke. Front. Mater. 5:14. doi: 10.3389/fmats.2018.00014

\section{Harnessing the Potential of Biomaterials for Brain Repair after Stroke}

\author{
Anup Tuladhar ${ }^{1 t}$, Samantha L. Payne ${ }^{1,2 t}$ and Molly S. Shoichet $t^{1,2,3 *}$ \\ ${ }^{1}$ Institute of Biomaterials and Biomedical Engineering, University of Toronto, Toronto, ON, Canada, ${ }^{2}$ Department of Chemical \\ Engineering and Applied Chemistry, University of Toronto, Toronto, ON, Canada, ${ }^{3}$ Department of Chemistry, University of \\ Toronto, Toronto, ON, Canada
}

Stroke is a devastating disease for which no clinical treatment exists to regenerate lost tissue. Strategies for brain repair in animal models of stroke include the delivery of drug or cell-based therapeutics; however, the complex anatomy and functional organization of the brain presents many challenges. Biomaterials may alleviate some of these challenges by providing a scaffold, localizing the therapy to the site of action, and/or modulating cues to brain cells. Here, the challenges associated with delivery of therapeutics to the brain and the biomaterial strategies used to overcome these challenges are described. For example, innovative hydrogel delivery systems have been designed to provide sustained trophic factor delivery for endogenous repair and to support transplanted cell survival and integration. Novel treatments, such as electrical stimulation of transplanted cells and the delivery of factors for the direct reprogramming of astrocytes into neurons, may be further enhanced by biomaterial delivery systems. Ultimately, improved clinical translation will be achieved by combining clinically relevant therapies with biomaterials strategies.

Keywords: stroke, regeneration, biomaterials, drug delivery, cell delivery

\section{ISCHEMIC STROKE}

\section{Physiology and Pathology}

Brain injury, unlike degenerative conditions that manifest as a gradual decline in tissue function, is a sudden event resulting in a permanent loss of tissue and functional deficits. The brain is a particularly challenging organ to develop therapeutics for due to its limited capacity for self-repair, the presence of the blood-brain barrier (BBB), as well as its inherently complex cellular and functional composition. A stroke is caused by local oxygen deprivation in the brain due to either hemorrhaged or occluded blood vessels, accounting for 13 and 87\% of strokes, respectively (Mozaffarian et al., 2016). Within

Abbreviations: BBB, blood-brain barrier; BDNF, brain-derived neurotrophic factor; BMP4, bone morphogenic protein 4; ChABC, chondroitinase ABC; CSPG, chondroitin sulfate proteoglycan; ECM, extracellular matrix; EGF, epidermal growth factor; EPO, erythropoietin; ESC, embryonic stem cell; FGF2, fibroblast growth factor 2; GDNF, glial-derived neurotrophic factor; GFAP, glial fibrillary acidic protein; HA, hyaluronan; HAMC, hyaluronan methylcellulose; hCG, human chorionic gonadotrophin; HGF, hepatocyte growth factor; IGF, insulin growth factor; iPSC, induced pluripotent stem cell; MC, methylcellulose; MMP, matrix metalloproteinase; MRI, magnetic resonance imaging; MSC, mesenchymal stromal cell; NPC, neural progenitor cell; NSC, neural stem cell; NSPC, neural stem/progenitor cell; NT-3, neurotrophin-3; PCL, polycaprolactone; PDMS, polydimethylsilosane; PEG, polyethylene glycol; PGA, polyglycolic acid; PLGA, poly(D,L-lactic acid co-glycolic acid); PSA, poly(sebacic acid); SAP, self-assembling peptide; CSF, cerebrospinal fluid; SDF-1 $\alpha$, stromal-derived factor-1 $\alpha$; SGZ, subgranular zone; STAiRS, Stroke Therapy Academic Industry Round Table; SVZ, subventricular zone; TBI, traumatic brain injury; TMS, transcranial magnetic stimulation; tPA, tissue plasminogen activator; VEGF, vascular endothelial growth factor. 
minutes following the depletion of blood flow, neurons and glial cells undergo apoptosis and necrosis, resulting in the formation of a cavity or infarct (Barkho and Zhao, 2011). The cellular and tissue events that follow the onset of a stroke can be categorized into three phases: acute, subacute, and chronic (Heiss, 2012).

The acute phase of stroke is characterized by rapid cell death, breakdown of the $\mathrm{BBB}$, and infiltration of immune cells into the infarct. Hypoxia and the resulting energy deficit triggers a cascade of cell necrosis to form a infarct (Heiss, 2012; Xing et al., 2012). Cellular excitotoxicity occurs as glutamate is released by dying neurons into the extracellular matrix (ECM) and reuptake is inhibited, resulting in high intracellular calcium concentrations. By $6 \mathrm{~h}$ poststroke, the majority of cell death has occurred (Heiss, 2012; Hossmann, 2012). However, in the hours and days after a stroke there is continued cell death and impaired function in the area surrounding the infarct core, known as the peri-infarct. The peri-infarct contains cells that are impaired but can be potentially restored using therapeutic strategies (Touzani et al., 2001; Brouns and De Deyn, 2009).

In the subacute phase, waves of neuronal depolarization trigger further cell injury, caspase-mediated cell apoptosis and cell necrosis, which propagate from the ischemic core into the periinfarct (Velier et al., 1999). Several molecular cascades contributing to cell death are initiated at this time, including free radical production, excitotoxicity, release of cytokines, and infiltration of macrophages and microglia causing inflammation and gliosis (Besancon et al., 2008; Barkho and Zhao, 2011).

The last phase of a stroke is the delayed injury or chronic phase, occurring in the weeks following the initial occlusion (Heiss, 2012; Kanekar et al., 2012). In this phase, there is widespread edema and activation of proteases and cytokines. Oxidative stress activates matrix metalloproteinases (MMPs), which disrupt tight junctions between cells and the basal lamina, and lead to a secondary breakdown of the BBB. Breakdown of the BBB in turn causes leakage of plasma, red blood cells, and infiltration of immune cells into the brain parenchyma (Brouns and De Deyn, 2009; Heiss, 2012). Once in the brain, neutrophils and other leukocytes release proinflammatory factors, initiating a secondary wave of inflammation (Doyle et al., 2008; Brouns and De Deyn, 2009). There are also changes to the brain ECM that occur over time following stroke. As the basement membrane around blood vessels is degraded, collagen IV and laminin are reduced, and fibrinogen is deposited and converted to fibrin (Baeten and Akassoglou, 2011). High-molecular-weight hyaluronan (HA) is deposited in the interstitial ECM and contributes to chondroitin sulfate proteoglycan (CSPG)-mediated restriction in plasticity and regrowth of axons (Lau et al., 2013). These changes can persist in the stroke infarct, and although the majority of tissue loss occurs early in the injury process, it has been shown in humans that gradual tissue loss can continue years after the initial stroke (Seghier et al., 2014).

\section{Current Clinical Treatments}

Despite the high prevalence of stroke in North America, clinical therapies remain limited. The only FDA-approved treatment for ischemic stroke is tissue plasminogen activator (tPA), which activates plasminogen by catalyzing its conversion into plasmin, improving the outcome in ischemic stroke when administered up to $4.5 \mathrm{~h}$ following stroke (Stemer and Lyden, 2010). Due to the narrow therapeutic window and risk of bleeding associated with tPA, only 3-6\% of stroke patients are eligible for tPA administration (de Los Ríos la Rosa et al., 2012). An endovascular thrombectomy can be performed as a complement to tPA for larger vessel occlusions, but this strategy is also time-dependent (Meretoja et al., 2017). Rehabilitation to regain function and encourage remodeling of the neural circuitry is also utilized following a stroke. Low-intensity training begins around $72 \mathrm{~h}$ after a stroke, followed by additional rehabilitation programs for up to 2 months poststroke (Winstein et al., 2016). While many of the aforementioned therapies are successful, they do not promote sufficient regeneration of brain tissue to completely restore function to the brain.

\section{Barriers to Regeneration Blood-Brain Barrier}

The $\mathrm{BBB}$ serves as a gatekeeper between the brain and circulating blood. The three main components of the BBB (endothelial cells, astrocytic end-feet, and pericytes) interact to form and maintain the tight junctions between endothelial cells which permit the diffusion of dissolved gases such as $\mathrm{O}_{2}$ but limit the transport of large molecules (Ballabh et al., 2004). Following a stroke there is breakdown of the BBB leading to a lack of vascular support, infiltration of immune cells, and ultimately the formation of a cavity (Brouns and De Deyn, 2009). The loss of BBB integrity also limits the use of tPA due to the risk of causing a lethal hemorrhage in a blood vessel (Cheng et al., 2014). After two waves of hyperpermeability, the first at $4-6 \mathrm{~h}$ and a second delayed permeability at 24-72 h (Kuroiwa et al., 1985; Krueger et al., 2013), the BBB is gradually reestablished.

\section{Reactive Astrocytes}

Injury to the central nervous system (CNS) activates quiescent astrocytes, which undergo morphological changes to become reactive in the peri-infarct region as early as one day after stroke (Duggan et al., 2009; Barreto et al., 2011), forming a physical and chemical barrier, known as the glial scar (Yasuda et al., 2004). Reactive astrocytes and pericytes secrete proteoglycans, such as CSPGs, that inhibit axonal outgrowth, making their degradation a target for regenerative strategies (Fawcett and Asher, 1999; Zhang and Chopp, 2009). Perineuronal nets, a normal component of the brain ECM, also inhibit axon regeneration (Liu et al., 2006). However, reactive astrocytes can also play a positive role following stroke, isolating the injury site to prevent the spread of degeneration into healthy tissue, and secreting many growth-promoting proteins that can stimulate axonal sprouting (Lu et al., 2003; Liu et al., 2014). Since the sequence of release of both growth inhibiting and growth promoting molecules by endogenous reactive astrocytes is spatiotemporally coordinated, designing a strategy that targets astrocytes at the optimal time for therapeutic results is challenging.

\section{Endogenous Response}

Following a stroke, a considerable amount of circuit remapping takes place in both animal models (Winship and Murphy, 2008) 
and humans (Dancause et al., 2005). This includes local axonal sprouting and remodeling in areas adjacent to the injury, as well as larger-scale hyperactivation of contralateral motor pathways (Tombari et al., 2004; Dancause et al., 2005). This rewiring can serve as a compensatory mechanism to redirect functional pathways of the brain but is often insufficient to induce meaningful recovery (Winhuisen et al., 2005).

It has been demonstrated in both rodents and humans that the brain attempts to replace lost cells through the stimulation of endogenous neural stem and progenitor cells (NSPCs) found in the subventricular zone (SVZ) of the lateral ventricles and the subgranular zone (SGZ) of the dentate gyrus (Morshead et al., 1994; Chiasson et al., 1999; Arvidsson et al., 2002; Yamashita et al., 2006; Minger et al., 2007). The cells of the SVZ normally function to continually replace neurons of the olfactory bulb by migrating along the rostral migratory stream, but newly-born neuroblasts will be redirected to areas of ischemia in the striatum and cortex following injury (Pencea et al., 2001; Bedard and Parent, 2004; Kernie and Parent, 2010). In animal models, the time of NSPC activation will vary depending on the type and size of injury, from 5 to 7 days posthypoxic/ischemic injury (Ikeda et al., 2005) and 2 and 6 weeks after middle cerebral artery occlusion injury (Li et al., 2010). Due to the presence of cytotoxic factors and a lack of supportive ECM, the majority of NSPCs from the SVZ do not survive past 2 weeks (Arvidsson et al., 2002; Parent et al., 2002; Guerra-Crespo et al., 2012) and their ultimate contribution to regeneration is suggested to be minimal (Wernig et al., 2004; Bithell and Williams, 2005; Bliss et al., 2010; Kernie and Parent, 2010). The cells of the SGZ, thought to be primarily neural progenitor cells (NPCs) (Nakatomi et al., 2002), actively regenerate neurons in the granular layer of the adult hippocampus and are activated following an ischemic insult (Lindvall and Kokaia, 2010). While there is evidence of neurogenesis in the hippocampus after global ischemia, the cells in the SGZ do not change their normal migratory pathway following injury (Wiltrout et al., 2007), limiting their therapeutic potential beyond hippocampal injury.

\section{Biomaterials for Brain Repair}

The goal of regenerative medicine therapies after stroke is to increase the amount of functional tissue available for recovery of lost neurological function. This is achievable by: (1) protecting degenerating neural cells in the peri-infarct region, (2) regenerating new tissue to replace lost neural cells using endogenous or exogenous stem cells, and (3) creating a growth-permissive environment for new neural cells and circuitry to survive and integrate into the host tissue.

Strategies for promoting repair have revolved around delivery of drugs (proteins, antibodies, and small molecules) and cells. While promising, progress has been hindered by multiple challenges. Drug therapies are severely impeded by the restriction of drug diffusion into the brain parenchyma by the $\mathrm{BBB}$, rendering most systemically administered therapies ineffective. Cell transplantation is limited by poor survival after delivery, a loss of supportive ECM and vasculature in the injured brain, and difficulty achieving maturity and integration into host tissue.

Biomaterials refer to a class of materials that are tailored to provide a beneficial effect in the targeted biological system. They can be utilized in the brain as scaffolds to provide mechanical stability to the injured brain, to provide a substrate for endogenous repair, and to address challenges in drug and cell therapies. Namely, they can be used to: bypass the $\mathrm{BBB}$, provide temporal control over drug delivery, localize drug and cell therapies to targeted sites, reduce the negative effects of the hostile microenvironment, increase drug stability and cell survival, provide modulatory cues to the brain, serve as scaffolds to endogenous and exogenous stem cells, and provide guidance cues for the creation of new neural circuits.

\section{Material Properties of the Brain}

The brain is one of the softest tissues in the body, with an elastic modulus reported in the range of $0.1-500 \mathrm{~Pa}$ in rodents (Christ et al., 2010) and 1-14 kPa in humans (Hiscox et al., 2016). The brain has a structurally heterogeneous anisotropy with distinct regions that vary in cellular composition and stiffness. Differences in stiffness are most pronounced between the cell-body containing gray matter and axon-dense white matter ( $\sim 500 \mathrm{~Pa}$ in the gray matter of the rat brain versus $\sim 300 \mathrm{~Pa}$ in the white matter; Kruse et al., 2008; Christ et al., 2010), but substantial variation exists even within the same anatomical structure (Elkin et al., 2007). The anisotropy of the brain is also reflected in the inhomogeneous diffusion parameters; for example, diffusion in the corpus callosum occurs more readily in parallel with the axon bundle than perpendicular to it (Syková and Nicholson, 2008). The structural integrity of the brain is mediated by the ECM, which consists primarily of collagen type IV, HA, fibronectin, laminin, and proteoglycans such as CSPGs (Lau et al., 2013; Medberry et al., 2013). These molecules may be subdivided into three compartments with differing function: (1) the basement membrane that binds the CNS parenchyma and the vasculature, composed of collagen, laminin, fibronectin, and proteoglycans; (2) perineuronal nets that surround neuronal cell bodies, dendrites, and synapses, made primarily of CSPGs; and (3) the interstitial matrix that contains a network of molecules loosely bound to the basement membrane or perineuronal nets, consisting of proteoglycans, HA, and small amounts of collagen, elastin, laminin, and fibronectin (Lau et al., 2013). The composition of the brain ECM is important in the injury response; whilst scar tissue in most regions of the body (i.e., skin, heart, muscle) is typically stiffer than the surrounding healthy tissue, the glial scar is actually softer than healthy tissue. This may be partly due to the lack of fibrous collagen type I in the brain (Moeendarbary et al., 2017).

\section{Design Criteria for Brain Biomaterials}

The delicate nature of brain tissue and the confined space of the skull imposes a unique set of design criteria for biomaterial use in the brain. The criteria for the material depend on the type of therapy but some common features emerge. The material should be biocompatible with brain tissue, which is more sensitive to mechanical and environmental stresses than other tissues (Saxena and Caroni, 2011). For maximum biocompatibility, the mechanical properties of the material should be similar to those of brain tissue, as stiffer materials lead to increased gliosis and worsened outcomes, whereas materials softer than the host tissue lead to poor material stability at the implant site (Moshayedi 
et al., 2016; Spencer et al., 2017). Due to the confined space of the skull the material must also be minimally swelling to avoid compressing the brain tissue and increasing intracranial pressure. Injectable and shape-adaptable materials are favored over stiff implants because they require less invasive surgical procedures and can conform to heterogeneous spaces. The material must be degradable and resorbable as it has been demonstrated that long-term or non-biodegradable implants, such as those made from silicone, leads to chronic inflammation, scarring, and neuron death (Biran et al., 2005). Additionally, the degradation products must also be non-cytotoxic. The immunogenicity of the material has a significant impact on its biocompatibility. Although some inflammation is inevitable, this response can be reduced by choices in material design, such as having physical properties similar to native brain tissue (i.e., low modulus and elastic in nature) and low interfacial tension with biological fluids to minimize immune cell adhesion.

The intended use of the material will determine the importance of its properties. For drug delivery, the ability to control drug release is important for regenerative therapies and is largely dependent on material stability, drug solubility, and tissue penetration. For protein therapeutics the ability to shield against enzymatic degradation, especially in the acutely injured brain, is crucial. Yet, some materials or chemistries necessary for controlled drug release are incompatible with cell delivery due to degradation by-products or harsh fabrication conditions (Bible et al., 2012; Pakulska et al., 2013). For cell delivery, the material must be cytocompatible, able to promote cell adhesion to prevent anoikis, able to provide good cell distribution in order to prevent cell aggregation (often observed with transplants in saline; Ballios et al., 2015), and degradable. Topographical features, bioactive ligands, or drugs incorporated into the material can be used to guide cell behavior and fate. Finding a material with all the desired properties is challenging, thus requiring the mechanical and chemical properties to be tuned.

\section{Types of Biomaterials Used in the Brain}

Biomaterials can be produced from both natural and synthetic materials. Natural materials are derived from ECM components (e.g., HA, collagen, fibrin, laminin, heparin, peptides, and proteins) or from xenobiotic sources [e.g., alginate, chitosan, Matrigel ${ }^{\mathrm{TM}}$, silk, methylcellulose (MC)]. Naturally derived polymers are advantageous over synthetic polymers because they are made of components of the ECM or have properties similar to the ECM and are therefore less likely to stimulate an immune response (Nair and Laurencin, 2007). Synthetic biomaterials for the brain are commonly made of polyethylene glycol (PEG), poly(D,L-lactic acid), polyglycolic acid (PGA), poly(D,L-lactic acid co-glycolic acid) (PLGA), poly(D-lysine), poly(sebacic acid) (PSA), and polycaprolactone (PCL) (Drury and Mooney, 2003; Hoffman, 2012). Synthetic polymers are easier to tune and possess superior in vivo stability. Though they lack innate ECM components necessary for cell survival (such as adhesive ligands to prevent anoikis), they can be functionalized with bioactive ligands (Hoffman, 2012). Biomaterials used in the brain can take on the form of injectable hydrogels, nano- and microparticles, and electrospun fibers.
Hydrogels are of particular interest as scaffolds for tissue engineering and drug delivery because they are able to form ECM-mimetic architectures. They are polymer networks crosslinked via chemical bonds or physical interactions and are primarily composed of water. Their porous and shape adaptable nature is effective for filling the stroke cavity and allows diffusion of oxygen, nutrients, and drugs required by transplanted and host cells (Drury and Mooney, 2003). They can often be tuned to match the mechanical properties of the brain (Tyler, 2012). Hydrogel stability is dependent, in part, on the number of the crosslinks formed; generally, physically crosslinked gels are less stable than chemically crosslinked gels, but the chemistry required for crosslinking can be detrimental to encapsulated proteins and cells, and, in some cases, the host tissue (Lee and Mooney, 2001). The crosslinking method also affects the rheological properties of the gel; in situ crosslinking is preferred as it allows the gel to be injected and conform to the space (Stabenfeldt et al., 2006). Ultraviolet crosslinking can be used to chemically crosslink gels in situ, but this method has not been extensively used in the brain due to limited UV light penetration. In addition to taking advantage of their innate properties, hydrogels can be modified with customizable factors such as proteins or peptides using a number of methods, including: blending, adsorption, electrostatic interaction, chemical modification such as Schiff base reaction (Stabenfeldt et al., 2006), Diels-Alder click chemistry (Nimmo and Shoichet, 2011), covalent modifications (Tam et al., 2012), and/or affinity-based binding (Vulic and Shoichet, 2014). These modifications promote host interactions, support cell transplantation and control drug release.

Other polymeric biomaterials have been used extensively in drug delivery and tissue engineering as well; namely, particles and electrospun fibers. Particles are typically used for drug delivery and range in size from hundreds of nanometers to hundreds of micrometers (Soppimath et al., 2001; Taluja et al., 2007). Synthetic polymers are the most widely used material for forming particles. Block copolymers of PLGA are widely used in the field of controlled drug delivery because they are one of the few biodegradable polymers approved for clinical use by the FDA (Langer, 1990; Cohen-Sela et al., 2009). The degradation rate of polymeric particles is typically tuned by varying the particle size and composition. A common concern with PLGA is acidification of the local environment due to its acidic degradation products, potentially causing further cellular and tissue damage; however, this is a concern mostly for larger polymeric implants vs. nano/ micro-particles where the acidic products can diffuse away. Particles made of natural materials, such as heparin (Hettiaratchi et al., 2014) and chitosan (Mo et al., 2010), avoid this issue but are less commonly used, in part due to their limited tunability. Synthetic material-derived electrospun scaffolds are attractive because their nanofibrous structure can recapitulate the microstructure of neural networks and can guide axons and neurites topographically (Schnell et al., 2007; Nisbet et al., 2009). Cell migration into these scaffolds is limited, but may be enhanced by inclusion of electrospun fibers in hydrogels, resulting in a cellpermissive scaffold that retains the biomimetic microstructure (Bosworth et al., 2013). 


\section{DRUG DELIVERY}

\section{Goals of Drug Therapy}

Drug therapy utilizes endogenous repair mechanisms for protecting neural cells, creating a growth permissive environment, stimulating endogenous neural stem cells (NSCs), and promoting brain rewiring and plasticity. The therapeutics may take the form of small molecules, peptides or proteins. However, the BBB limits tissue penetration of systemically-administered therapeutics, rendering conventional systemic delivery strategies (intravenous and oral) ineffective (Pardridge, 2012). The small fraction of drugs that cross the $\mathrm{BBB}$ are often exported by surface transporters on the $\mathrm{BBB}$, such as G-protein-coupled receptors (Misra et al., 2003). Large systemic doses can increase drug diffusion across the $\mathrm{BBB}$ but many compounds carry risks of systemic toxicity. Modifications to drugs and carrier-mediated transport across the BBB (Pardridge, 2003) may improve delivery but still expose the body to non-specific effects of the drug and require large doses due to systemic dilution. BBB breakdown after stroke does increase diffusion into the brain parenchyma, but is limited to the infarcted tissue and a narrow window of opportunity for administration; with reestablishment of the BBB, systemic delivery of therapeutics is again limited (Pardridge, 2012). Similarly, methods to disrupt the $\mathrm{BBB}$, such as hypotonic solutions or focused ultrasound (Vykhodtseva et al., 2008), are non-specific and render the CNS vulnerable to circulating pathogens, making them unsuitable for sustained drug therapies.

Circumventing the BBB with local drug delivery increases the amount of drug at the target site, reducing systemic exposure and the risk of systemic toxicity. Clinical methods administer drugs by intracerebroventricular or intracortical infusion through a catheter (the Ommaya reservoir; Mead et al., 2014). These routes are fraught with issues, as fluid injection into the small ventricular spaces increases intracranial pressure and has been associated with hemorrhage, leakage of cerebrospinal fluid (CSF), and infection (Misra et al., 2003; Mead et al., 2014). Additionally, there is evidence that administration of drug into the CSF does not necessarily increase drug transport into the brain parenchyma (Pardridge, 2011). Convection enhanced delivery has been tested as a solution to increase drug distribution into the brain parenchyma by using a pressure gradient to drive convective transport through the interstitial spaces in the brain, achieving tissue penetration up to several centimeters vs. the millimeter range observed with diffusive transport (Mehta et al., 2017). However, this method is only conducive to bolus injections and cannot provide sustained delivery. Additionally, problems of increased intracranial pressure, damage to the infusion site, and damage due to needle insertion into brain tissue are still present.

Biomaterials that can be used for sustained local drug delivery to the brain in a minimally invasive manner have become important for drug therapy because they address many of the challenges surrounding delivery. Here, we discuss the use of biomaterials to improve local drug delivery and control drug release. We focus on the advances that have been made using biomaterials and drugs to: (1) protect cells, (2) stimulate regeneration, and (3) promote plasticity (Table 1). The therapeutic effects of biomaterials on host tissue will also be discussed.

\section{Local Drug Delivery to the Brain}

Biomaterial-based local drug delivery systems can overcome the limitations of traditional catheter-based systems. Drug diffusion in the brain is affected by the size (38-64 $\mathrm{nm}$ between cells) and tortuosity ( $\lambda=\sim 1.7$ in uninjured brain, $\sim 2.1$ in injured brain) of the extracellular space, interactions with cellular receptors, and affinities for charged moieties in the ECM (Thorne et al., 2008). Brain injury will change these parameters and reduce the effective diffusivity, thereby making it difficult to achieve therapeutic concentrations at distances greater than several centimeters. Tissue penetration - the distance the drug is found from the source at detectable concentrations-can be enhanced by increasing the drug concentration at the source, reducing binding to the ECM, or decreasing elimination and degradation. Providing a sustained source of drugs would maintain a higher driving force for diffusion and increase penetration. Shielding the protein from extracellular degradation can increase effective diffusion, as was shown by the threefold increased tissue penetration after PEGylating epidermal growth factor (EGF) (Wang et al., 2011b). In some cases, it is important to control the spatial distribution of the molecule, not just the tissue penetration, as this can profoundly affect physiological response. For example, mice expressing vascular endothelial growth factor-A (VEGF-A) isoforms with high ECM binding affinity, with steep concentration gradients and low tissue penetration, exhibited thin, highly branched blood vessels while non-ECM binding VEGF isoforms, with shallow concentration gradients and higher concentrations further away from the source, exhibited wide, leaky vessels (Ruhrberg et al., 2002).

Delivery can take two forms: intracranial delivery and epicortical delivery (Figure 1). Intracranial delivery into the stroke infarct limits damage to healthy tissue. As the peri-infarct region is often the site of many protective and regenerative therapies (Carmichael et al., 2005), this also positions the drug closer to the site of action and reduces the diffusion distance, ensuring therapeutically relevant concentrations are reached. One limitation of intracranial delivery is the limited range of drug transport by diffusion (in the range of millimeters) that is adequate for animal models but may not scale to the larger human brain. However, postinjury plasticity is often mediated by the peri-infarct tissue located millimeters to tens of millimeters from the infarct boundary zone (Nudo et al., 1996; Luft et al., 2004; Carmichael et al., 2005; Brown et al., 2009). Thus, in most cases, the diffusive range seen in animal models may be translatable to humans.

Epi-cortical delivery has been explored as a minimally invasive method of drug delivery to the brain (Cooke et al., 2011; Tuladhar et al., 2015). With this method a drug-loaded scaffold is implanted onto the surface of the brain, thus avoiding tissue damage caused by needle insertion as is seen with intracranial and convection-enhanced delivery. In the mouse and rat, proteins and drugs delivered epi-cortically can diffuse through the cortex and reach the subcortical NSPCs located in the lateral ventricles. A drawback of this approach is the larger diffusion distance required to reach the site of action. Although this method may not be amenable to targeting the subcortical ventricles in the larger human brain due to limits of diffusive transport, treatments targeting the thin (1-5 mm) cortical regions of the human brain (Fischl and Dale, 2000) may be amenable to epi-cortical delivery. 
TABLE 1 | Biomaterials for local drug delivery to the brain.

\begin{tabular}{|c|c|c|c|}
\hline Therapeutic & Material description & Outcome & Reference \\
\hline CsA & $\begin{array}{l}\text { CsA-loaded PLGA microparticles inside HAMC hydrogel } \\
\text { implanted epi-cortically in Et-1 stroke-injured mouse and } \\
\text { rat }\end{array}$ & $\begin{array}{l}\text { Controlled local delivery for } 2-3 \text { weeks, reduced stroke infarct } \\
\text { volume, proliferation increased in rat NSPC niche with CsA, } \\
\text { reduced infarct volume with HAMC }\end{array}$ & $\begin{array}{l}\text { Caicco et al. } \\
(2013) \text { and } \\
\text { Tuladhar et al. } \\
(2015)\end{array}$ \\
\hline EGF & $\begin{array}{l}\text { EGF-loaded HAMC hydrogel implanted epi-cortically in } \\
\text { Et-1 stroke-injured mouse }\end{array}$ & $\begin{array}{l}\text { PEG-modified EGF increased diffusion distance during 2-d } \\
\text { release, increased proliferation of neuroblasts in SVZ }\end{array}$ & $\begin{array}{l}\text { Cooke et al. (2011) } \\
\text { and Wang et al. } \\
\text { (2011b) }\end{array}$ \\
\hline EPO & $\begin{array}{l}\text { EPO HAMC hydrogel implanted epi-cortically in Et-1 } \\
\text { stroke-injured mouse }\end{array}$ & $\begin{array}{l}\text { EPO released to brain for } 2 \text { days, stroke cavity volume } \\
\text { decreased with HAMC; further decreased with EPO. Reduced } \\
\text { astrogliosis and microglia response with HAMC, increased } \\
\text { number of proliferating neuroblasts in SVZ, reduced cell death } \\
\text { in SVZ and more neurons }\end{array}$ & $\begin{array}{l}\text { Wang et al. } \\
\text { (2012b) }\end{array}$ \\
\hline EGF + EPO & $\begin{array}{l}\text { EGF loaded PLGA nanoparticles and EPO loaded } \\
\text { PLGA/PSA microparticles inside HAMC hydrogel } \\
\text { implanted epi-cortically at } 4 \text { days poststroke in Et-1- } \\
\text { injured mouse }\end{array}$ & $\begin{array}{l}\text { Sequential and sustained release of PEG-EGF followed by } \\
\text { EPO. Increased number of NSPCs in SVZ niche and increased } \\
\text { proliferation. Reduced cavity size with EGF + EPO vs. vehicle } \\
\text { and more neurons }\end{array}$ & Wang et al. (2013) \\
\hline \multirow[t]{2}{*}{ VEGF } & $\begin{array}{l}\text { Alginate hydrogel loaded with VEGF }{ }_{165} \text { by premixing } \\
\text { alginate solution with lyophilized VEGF and crosslink } \\
\text { at RT for } 30 \text { min, kept on ice until injected into striatum } \\
15 \text { min before MCAO in young adult male SD rats }\end{array}$ & $\begin{array}{l}\text { VEGF }_{165} \text { released from hydrogel found in brain for } 1 \text { week } \\
\text { compared to }<10 \mathrm{~h} \text { from bolus injection, resulting in reduced } \\
\text { infarct volume and reduced neurological deficit }\end{array}$ & $\begin{array}{l}\text { Emerich et al. } \\
(2010)\end{array}$ \\
\hline & $\begin{array}{l}\text { VEGF encapsulated in poly(dimethylsiloxane- } \\
\text { tetraethoxysilane) and injected into injury cavity }\end{array}$ & $\begin{array}{l}\text { Increased number of astrocytes and endothelial cells with } \\
\text { VEGF release. The PDMS-TEOS material helped restore/ } \\
\text { preserve brain shape, serving as a structural support }\end{array}$ & Zhang et al. (2007) \\
\hline $\begin{array}{l}\text { VEGF + Ang1 + Anti- } \\
\text { NOGOa }\end{array}$ & $\begin{array}{l}\text { HA hydrogel chemically crosslinked with reversibly } \\
\text { conjugated anti-NOGOa, loaded with VEGF and Ang1 } \\
\text { PLGA particles and implanted into MCAO-injured mice }\end{array}$ & $\begin{array}{l}\text { Increased angiogenesis with VEGF and Ang1, reduced } \\
\text { astrogliosis and microglial response and significant recovery } \\
\text { with Ang1 and VEGF treatment }\end{array}$ & Ju et al. (2014) \\
\hline Anti-NOGOa & $\begin{array}{l}\text { HA hydrogel chemically crosslinked with reversibly } \\
\text { conjugated anti-NOGOa }\end{array}$ & $\begin{array}{l}\text { Moderate behavioral recovery in a reaching task and increased } \\
\text { nerve fiber growth }\end{array}$ & Ma et al. (2007) \\
\hline BDNF & $\begin{array}{l}\text { HA hydrogel with collagen-binding domains to control } \\
\text { BDNF release, tested in mice and non-human primate }\end{array}$ & $\begin{array}{l}\text { Sustained BDNF release, over } 3 \text { weeks in mouse. Increased } \\
\text { axonal sprouting in contralateral striatum, following existing } \\
\text { axon patterns, concomitant with behavioral recovery. Increased } \\
\text { neurogenesis (DCX and NeuN + BrdU) }\end{array}$ & Cook et al. (2017) \\
\hline BDNF + AMPAkine & $\begin{array}{l}\text { HA hydrogel with collagen-binding domains to control } \\
\text { BDNF release, injected into infarct with AMPAkine } \\
\text { administered systemically in aged mice }\end{array}$ & $\begin{array}{l}\text { Recovery seen with both BDNF and AMPAkine alone, further } \\
\text { increased with combination. Increased expression of } \\
\text { proplasticity signaling (e.g., p-CREB, p-AKT) with BDNF, } \\
\text { AMPAkine, increased further in some cases by combination }\end{array}$ & $\begin{array}{l}\text { Clarkson et al. } \\
(2015)\end{array}$ \\
\hline BDNF + GDNF & $\begin{array}{l}\text { BDNF and GDNF were separately encapsulated in } \\
\text { PLGA particles to achieve different release rates and } \\
\text { loaded into a biodegradable PEG hydrogel strand, } \\
\text { injected into the substantia nigra and striatum of } \\
\text { uninjured female SD rats }\end{array}$ & $\begin{array}{l}\text { Achieved slow and long-term release of BDNF for over } \\
8 \text { weeks, and faster release of GDNF over } 28 \text { days. Swelling } \\
\text { was minimal. Slightly elevated astrogliosis but reduced } \\
\text { microgliosis }\end{array}$ & $\begin{array}{l}\text { Lampe et al. } \\
\text { (2011) }\end{array}$ \\
\hline NT-3 & $\begin{array}{l}\text { Chitosan microparticles loaded with NT-3 by adsorption } \\
\text { onto particle surface and suspended in a collagen-1 } \\
\text { solution, injected into infarct in hippocampal TBI model }\end{array}$ & $\begin{array}{l}\text { Chitosan carrier reduced gliosis and slightly increased axon } \\
\text { regeneration. NT-3 increased axon regeneration into the injury } \\
\text { site. Recovery in water maze task with chitosan carrier group; } \\
\text { no further recovery with NT-3 }\end{array}$ & Mo et al. (2010) \\
\hline HGF or IGF1 & $\begin{array}{l}\text { HGF or IGF1 absorbed to gelatin hydrogel microspheres } \\
\text { by incubation for } 1 \mathrm{~h} \text {. Injection into striatum of uninjured } \\
\text { and MCAO-injured mice. Drugs were tested } \\
\text { independently }\end{array}$ & $\begin{array}{l}\text { Increased number of neuroblasts with IGF1 or HGF only when } \\
\text { delivered in hydrogel carrier. No behavior tested }\end{array}$ & $\begin{array}{l}\text { Nakaguchi et al. } \\
(2012)\end{array}$ \\
\hline
\end{tabular}

\section{Controlling Drug Release}

Protective and regenerative therapies require sustained drug exposure to be efficacious (Wieloch and Nikolich, 2006). In the absence of control mechanisms, drugs given by bolus injection are cleared in several hours and drug release from a hydrogel depot is typically complete within $2-4$ days. The release window may be extended to several weeks or months by retarding diffusion out of the depot through encapsulation or immobilization in the matrix (Soppimath et al., 2001) or by affinity interactions with the matrix (Vulic and Shoichet, 2014).

Polymeric micro- and nano-particle systems control release by encapsulating drugs within a biodegradable polymer matrix. Drug release from bulk-degrading polymers, such as PLGA, involves multiple mechanisms (Han et al., 2016). The initial release, 

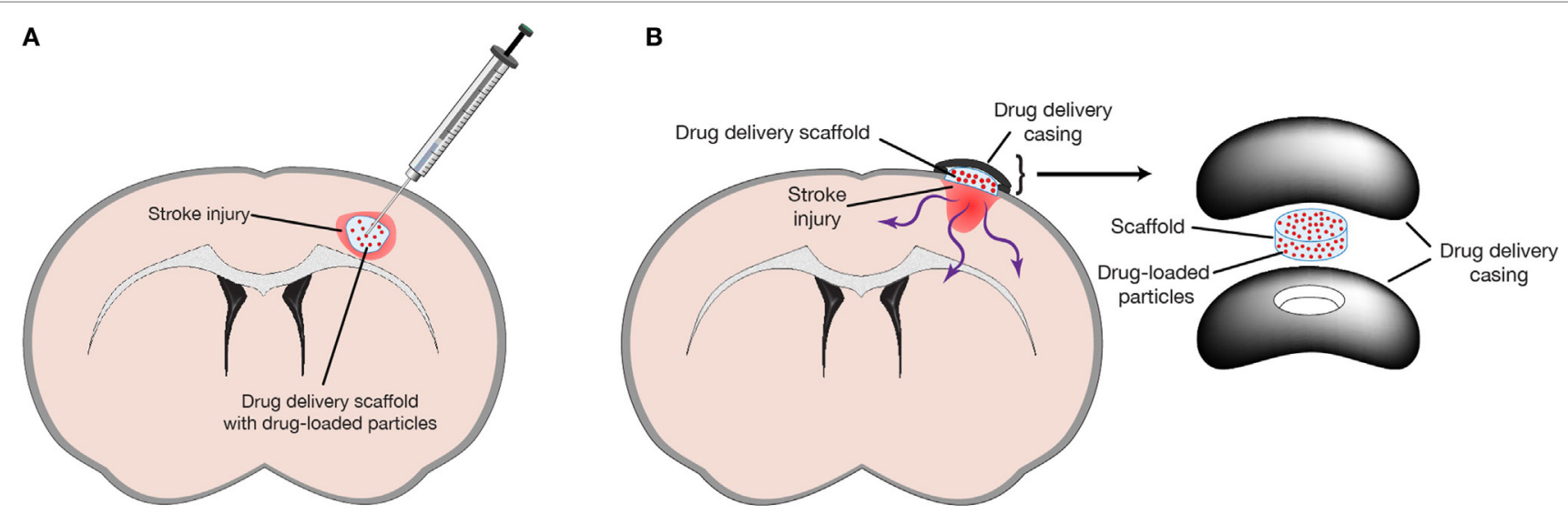

FIGURE 1 | Biomaterials can be used to delivery drugs by either (A) intracranial injection into space provided by the stroke injury or (B) epi-cortical implant on the surface of the brain to prevent any further damage due to injection. Reprinted from Tuladhar et al. (2015) with permission from Elsevier.

termed the burst phase, occurs from the surface bound drug and usually takes place within hours barring any interactions between drug and material. The next release phase occurs by diffusion of the drug through pores formed in the particle as the polymer degrades or swells. Finally, bulk degradation and polymer erosion results in the release of any remaining drug. Polymeric particles for drug release can range from several hundred nanometers to approximately $100 \mu \mathrm{m}$ (Soppimath et al., 2001; Taluja et al., 2007). Microparticles made from natural or ECM components, such as heparin and chitosan (Agnihotri et al., 2004; Lin et al., 2009), have been used but they lack the tunability of common synthetic materials such as poly(esters) (e.g., PLGA; Mohammadi-Samani and Taghipour, 2015) and poly(anhydrides) (e.g., PSA) (Kumar et al., 2002). The release period from PLGA particles can be tuned from 1 to 2 weeks to several months by varying the relative ratios of lactic acid and glycolic acid monomers, the copolymer chain length, the molecular weight of PLGA, or the terminal functional groups (Pollauf et al., 2005). Multiple drugs can be incorporated into the same particle and the use of slow and fast degrading PLGA variants allows for precise temporal release that better mimics signaling patterns found in vivo (Richardson et al., 2001; Lampe et al., 2011; Brudno et al., 2013). In addition, double-walled particles can be made using a mix of two polymers (Pekarek et al., 1994). Here, a drug-loaded core is coated with a drug-free shell; using a polyanhydride for the shell will result in a delayed release, where the surface eroding shell degrades before the drug is released from the core. Combining a classical PLGA particle with this double-walled particle allowed the sequential release of EGF followed a week later by erythropoietin (EPO) (Wang et al., 2013), mimicking the release paradigm of more invasive osmotic mini-pumps and cannulas used to stimulate endogenous brain NSPCs (Kolb et al., 2007) but in a minimally invasive manner.

Drugs can also be covalently immobilized within hydrogel matrices. The drug can act on cells at the hydrogel-tissue interface and on infiltrating cells. Immobilized proteins can cause a drastically different tissue response compared to soluble protein by inducing differential changes in receptor internalization and trafficking (Clegg and Mac Gabhann, 2015) and in downstream signaling pathways (Chen et al., 2010b). Proteins can be immobilized in a hydrogel using chemical conjugation (Ehrbar et al., 2007). Drug release is dictated by the rate of hydrogel degradation, which can be tuned to be environmentally responsive to enzymes [e.g., MMPs (Purcell et al., 2014)] secreted by, for example, NSPCs (Barkho et al., 2008) or endothelial cells (Rundhaug, 2005).

Naturally occurring affinity interactions between proteins and the ECM have been employed in biomaterials through natural or functionalized binding sites that control release through transient hydrophobic and electrostatic interactions. A key advantage of these systems is that the harsh encapsulation process necessary for particle systems is avoided, preserving protein function and stability. Release can be tuned by modifying the strength of the affinity interaction, the concentration of binding ligand, and the rate of dissociation (Vulic and Shoichet, 2014). Heparin is the most popular platform for affinity release because it has a natural affinity for a number of heparin binding proteins relevant for regeneration [e.g., fibroblast growth factor (FGF), VEGF, insulin growth factor (IGF), platelet-derived growth factor, stromalderived factor (SDF), and bone morphogenic proteins (BMPs); Capila and Linhardt, 2002]. It has been used to form hydrogels and particles or to functionalize other materials (SakiyamaElbert, 2014). To overcome the lack of specificity of heparin interactions, which is problematic in the heparin binding protein rich environment found in vivo, a variety of solutions have been pursued and include: heparan sulfate variants, selectively desulfated heparin, and heparin fractions with protein-specific affinity (Wang et al., 2014). A drawback to this approach is the limited ability to tune the strength of the heparin-protein interaction and the inherent limitation to heparin-binding proteins. The creation of fusion proteins with SH3-domains that interact with SH3-binding peptides bound to a gel enables specific affinity release strategies for a wider range of proteins (Vulic and Shoichet, 2012). This strategy allows for the controlled release of many proteins, including those too delicate for encapsulation and lacking affinity for heparin, as was demonstrated with the 
enzyme chondroitinase ABC (ChABC) (Pakulska et al., 2013). Multiple drugs can be released from the same vehicle with this system using the same material; however, the release rate of two or more drugs cannot be independently tuned. If the system is reversed whereby SH3-binding peptides are coexpressed with proteins and $\mathrm{SH} 3$ covalently bound to the hydrogel, controlled release of multiple proteins with independent release rates will be dictated by the unique SH3-binding peptide on each fusion protein (Delplace et al., 2016). Advances in computational design of protein-protein interactions and phage display libraries will increase the variety of binding interactions available for affinity release strategies, increasing their utility (Pakulska et al., 2016b). Recently, innovative work has used electrostatic interactions to control drug release from PLGA particles without the need for encapsulation (Pakulska et al., 2016a). The key advantage to this approach is the ability to control release of many relevant molecules [e.g., SDF, neurotrophin-3 (NT-3), and brain-derived neurotrophic factor (BDNF)] using the same nanoparticle, avoiding the harsh encapsulation process that often denatures proteins and reduces drug loading. Release can be tuned simply by varying nanoparticle size, concentration, and degradation rate. One limitation to the system is that the anionic particle can only interact with positively charged proteins. Modifying the particle with a positively charged component, such as chitosan, may allow electrostatic control of negatively charged proteins (Kumar et al., 2004). Laponite, derived from clay, can electrostatically control release of negatively charged proteins (Koshy et al., 2018), but the non-biodegradable silica degradation products make the platform incompatible with the brain.

\section{Protecting Neural Cells}

Neuroprotective strategies for stroke have been investigated to save existing cells and neural circuits by either (a) directly reducing cell death, demyelination, and axon death in the stroke peri-infarct or (b) mitigating secondary damage caused by excitotoxicity, inflammation, and oxidative stress. However, the utility of this approach was brought into question when it was noted, in 2006 , that although 1,026 neuroprotective agents had been identified and tested in preclinical studies (O'Collins et al., 2006) and almost 200 had reached various stages of clinical trial, nearly all had failed to demonstrate clinical efficacy. tPa, first tested in 1988, was the only exception (Stroke trials registry page, http://www. strokecenter.org/trials) (Minnerup et al., 2012). Discrepancies between preclinical and clinical studies (e.g., population age, scope of injury, and primary endpoint) likely contribute to the clinical failures (Sutherland et al., 2012). Despite the lack of clinical translation, neuroprotective strategies are still actively being investigated and evaluated using more targeted approaches based on mechanistic studies (Rajah and Ding, 2017).

The advent of biomaterials may give new life to neuroprotective molecules that have previously failed due to poor $\mathrm{BBB}$ penetration and low concentrations in poorly perfused ischemic regions. VEGF released from an alginate hydrogel provided exposure for 1 week, compared to $<10 \mathrm{~h}$ from a bolus injection, resulting in reduced stroke infarct size and neurological deficit (Emerich et al., 2010). The materials themselves offer some neuroprotection by providing structural support, attenuating gliosis and inflammation, and reducing cavitation. Bioactive materials, like HA, reduce inflammation through the CD44 receptor by inhibiting leukocyte migration and inflammation (Forrester and Wilkinson, 1981; Cooper et al., 2008), resulting in reduced microglial activation (Wang et al., 2012b) and stroke infarct volume (Hou et al., 2005; Austin et al., 2012; Wang et al., 2013; Tuladhar et al., 2015).

Recently, the effect of hydrogel structure alone on tissue repair was investigated by comparing a micro-porous HA hydrogel, synthesized by crosslinking HA-RGD microbeads in situ, to a nano-porous hydrogel while keeping the bulk moduli and biochemical signaling the same (Figures 2A-E) (Nih et al., 2017). Both structures reduced the thickness of the glial scar and degree of macrophage activation in the peri-infarct region; however, the magnitude of this effect was greatly increased in the microporous gel. Additionally, the microporous gel reduced macrophage activity within the stroke infarct. To have even greater benefit, neuroprotective drugs may be delivered from a microporous gel, as has been shown with gelatin microspheres to deliver anti-inflammatory (Jin et al., 2011b) or proregenerative molecules.

\section{Stimulating Endogenous Stem Cells}

Stimulating endogenous NSPC populations in the brain requires therapeutics to influence their proliferation, survival, migration, and differentiation (Wiltrout et al., 2007; Hunt and Morshead, 2010; Guerra-Crespo et al., 2012; Wang et al., 2012a). An array of growth factors and cytokines has been found to be important in endogenous NSPC signaling. Often, these factors have multiple and overlapping effects on the NSPCs. Many of the factors investigated for endogenous NSPC stimulation are naturally upregulated within hours to days after stroke as part of the injury response, but this is transient and in the majority of cases returns to basal levels within a week. These molecules include growth factors and cytokines to stimulate: proliferation [e.g., EGF, FGF2, VEGF, human chorionic gonadotrophin (hCG), hepatocyte growth factor (HGF), BDNF, IGF1], survival [e.g., VEGF, EGF, BDNF, glial-derived neurotrophic factor (GDNF)], migration (e.g., SDF1a, VEGF, BDNF), and differentiation (e.g., BDNF, EPO, GDNF, BMP4, HGF). The only drugs that have been tested clinically are hCG and EPO, and while preclinical results demonstrated increased endogenous NSPC mobilization and neuronal differentiation (Belayev et al., 2009), the clinical trial was inconclusive (Cramer et al., 2010). Although the clinical trial failed to demonstrate a benefit compared to saline controls, and was thus prematurely terminated, it was found in post hoc analysis that the subgroup of patients also receiving occupational therapy benefited from hCG and EPO treatment. Small molecule drugs clinically used for other therapeutic purposes have been found to stimulate NSPCs and promote recovery. Cyclosporine (CsA), a common immunosuppressant, is found to increase NSPC survival in vitro and in vivo, and to reduce stroke infarct volume (Hunt et al., 2010; Erlandsson et al., 2011; Sachewsky et al., 2014). Metformin, a drug for diabetes, stimulates neurogenesis in the hippocampus, improving memory in injured mice (Wang et al., 2012a); a clinical trial is underway to evaluate its potential in treating brain injury in children (NCT02040376). 

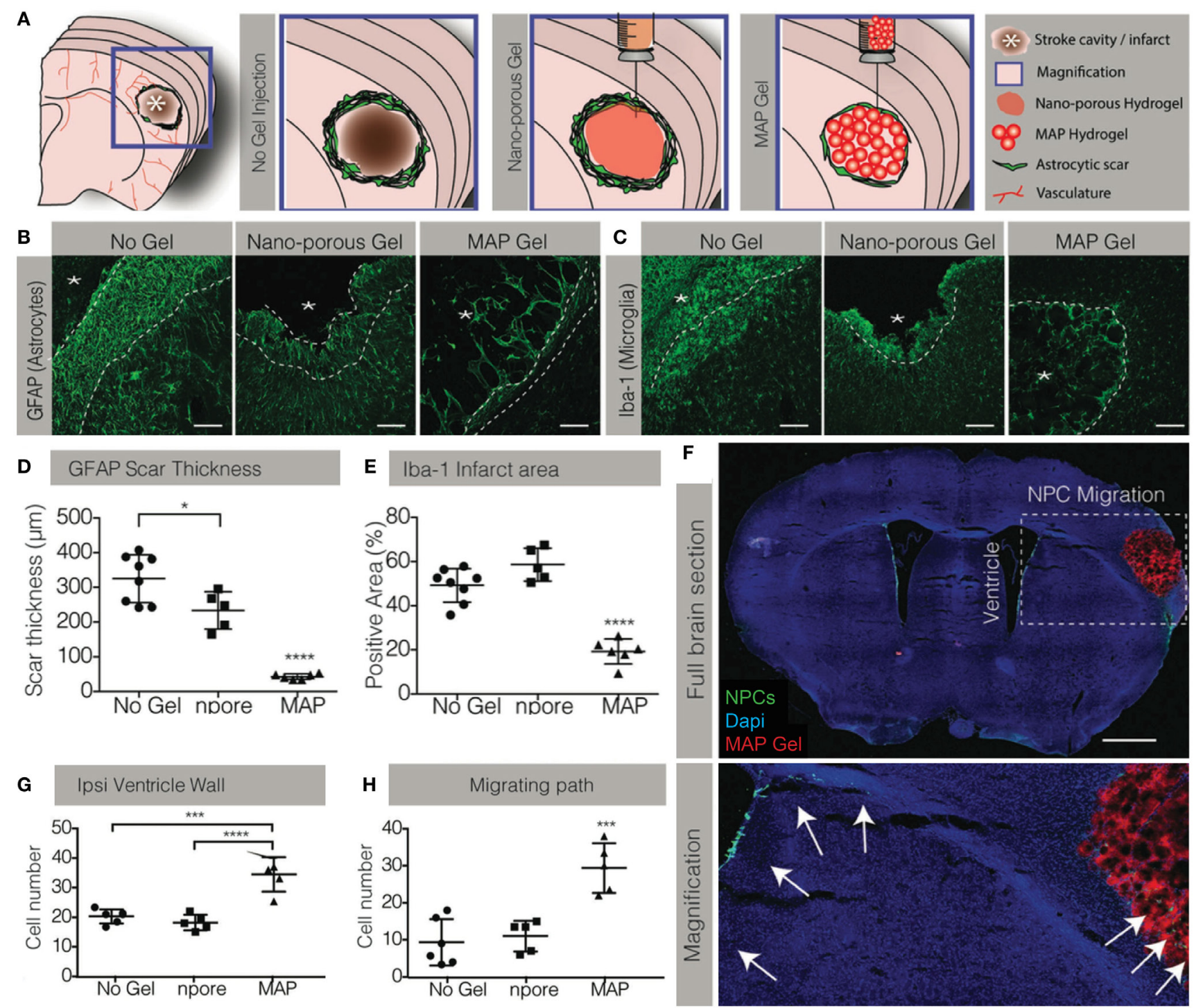

FIGURE 2 | Manipulating the biomaterial structure can drastically change the host response. (A) A microporous (MAP) hydrogel was synthesized using HA-RGD microbeads. The gel had the same bulk modulus and chemical structure as a nanoporous hydrogel. Representative images of the (B) astrocytic and (C) microglial responses in the stroke cavity with no gel, nanoporous gel and MAP gel. (D) The MAP hydrogel significantly reduced the glial scar thickness compared to the nanoporous hydrogel. (E) The microglial response was only reduced by the microporous MAP hydrogel; despite possessing the same modulus and biochemical signaling, the nanoporous hydrogel did not affect the response. (F) Representative images of endogenous neural progenitor cells (NPCs) stimulated by the MAP hydrogel. (G) Only the microporous MAP hydrogel increased the number of NPCs in the subventricular zone and (H) migrating into the infarct. Reproduced with permission from Nih et al. (2017).

Many studies have demonstrated improved outcomes when combining regenerative strategies with biomaterial delivery systems for controlled release of drugs. Controlled release of HGF and IGF1 from gelatin microspheres increased the number of neuronal progenitors while bolus IGF1 or HGF injections failed to stimulate the NSPCs (Nakaguchi et al., 2012). Although controlled release may be achieved through infusion strategies, this method is deleterious to the NSPC niche and may negate any beneficial effects of delivered factors (Wang et al., 2013). Intracortical BDNF injections can stimulate NSPCs but requires extended exposure (Schabitz et al., 1997). BDNF modified with a collagen binding domain increased retention in the tissue by binding to collagen in the ventricular NSPC niche, significantly stimulating NSPC proliferation and neurogenesis compared to unmodified BDNF that lacks the ability to bind to the niche (Guan et al., 2012). Incorporating the collagen binding domain in a HA hydrogel results in drug release over multiple weeks (Cook et al., 2017). Stroke-injured animals receiving BDNF from this hydrogel recovered motor function accompanied by NSPC proliferation and neurogenesis. However, because BDNF can exert recovery through a variety of mechanisms (e.g., synaptogenesis and angiogenesis) it is unclear how recovery was mediated. 
Epi-cortical EGF and EPO delivery with HAMC, a hydrogel blend of HA and methycellulose, increased NSPC proliferation and neurogenesis, but the short release window (2 days) may be insufficient for substantial regeneration and long-term recovery (Cooke et al., 2011; Wang et al., 2012b). Previous work with EGF and EPO demonstrated that sequential delivery of the two compounds into the ventricle with a cannula, for 7 days each, produced significant tissue regeneration and motor recovery (Kolb et al., 2007). Therefore, to mimic this release profile a composite delivery system using HAMC, PLGA nanoparticles, and doublewalled PLGA/polyanhydride microparticles was used to achieve sequential and extended release of EGF and EPO (Wang et al., 2013). This bioengineered strategy increased NSPC proliferation and survival compared to cannula delivery in a mouse model of stroke. This appears to be partly caused by reduced glial scarring and microglial activation by the vehicle, likely mediated by the HA component, and increased cell death in the SVZ due to cannula insertion. Controlled release of individual drugs was not tested, so it is unclear whether a synergistic effect of EGF and EPO was necessary for the effects reported. While a clear tissue benefit was seen, it is unknown whether this was accompanied by behavioral recovery. Epi-cortical delivery has also been tested in the larger rat model with cyclosporine, demonstrating sufficient tissue penetration to stimulate proliferating endogenous NSPCs (Tuladhar et al., 2015).

In a few cases, the material alone has had an impact on host NSPCs. The aforementioned micro-porous HA-RGD hydrogels stimulated NSPC proliferation in the SVZ-an effect not seen with nanoporous gels (Figures 2A,F-H) (Nih et al., 2017). While neuroblasts were reported to have migrated into the gels, it is unclear how the material stimulated NSPC proliferation. Aligned PCL nanofibers were used to promote NSPC migration into the injury site; however, long-term neuroblast survival required inclusion of a BDNF-mimetic peptide (Fon et al., 2014).

\section{Promoting Plasticity}

Neuroplasticity is defined as the brain's ability to modify its neural circuitry and is necessary to restore function (Dimyan and Cohen, 2011). Spared or newly generated tissue must be integrated into the uninjured neural network and adapt to functional demands. This requires the creation of new connections, modification of existing neural circuitry, and removal of plasticity inhibiting elements. Agonists of Trk receptors are involved in neuronal plasticity (Thoenen, 1995) and the two factors most investigated for stimulating this mechanism are NT-3 and BDNF. NT-3 has a key role in the development and repair of motor circuits (Patel et al., 2003; Chen et al., 2006) and delivery to stroke-injured animals increases axonal sprouting (Duricki et al., 2016). Chitosan particles suspended in a collagen 1 solution have been used to deliver NT-3 to the hippocampus in a traumatic brain injury (TBI) model (Mo et al., 2010). Interestingly, the chitosan particles alone resulted in increased axonal sprouting compared to injuryonly groups, while NT-3 further increased the amount of axon regeneration. However, behavioral recovery was significant with the chitosan vehicle alone and, surprisingly, the addition of NT-3 did not increase this recovery. This lack of additional recovery with NT-3 may not necessarily indicate that NT-3 is ineffective; rather, the axonal sprouting seen with chitosan may be sufficient for behavioral recovery and any additional improvement requires other mechanisms. In contrast, in a rat spinal cord injury model, a HAMC and PLGA-based NT-3 delivery system induced both axonal sprouting and motor recovery (Elliott Donaghue et al., 2015). The difference in outcomes may be due to differing etiologies in the two CNS compartments and different requirements for recovery.

Modifying existing neural circuits requires synaptic plasticity at axon-dendrite terminals to strengthen or weaken existing connections and appears to be mediated by BDNF. Delivering BDNF improves motor recovery (Müller et al., 2008) while blocking BDNF signaling reduces any recovery seen with plasticity-dependent rehabilitative training (Ploughman et al., 2009). Although BDNF expression is upregulated after stroke injury this effect is transient and is reduced with age, making plasticity-based recovery paradigms difficult in chronic stroke and aged populations. While systemically delivered AMPAkine stimulated recovery in young animals, by inducing BDNF release (Clarkson et al., 2011), recovery was dampened in aged animals (Clarkson et al., 2015) due to reduced BDNF expression in this population. Interestingly, combining the systemically administered AMPAkine with local BDNF delivery through a HA-based hydrogel modified with collagen-binding domains improved recovery in aged animals to levels comparable to young animals (Clarkson et al., 2015). This is one of the few studies involving biomaterials that investigated mechanistic pathways mediating this process, demonstrating that BDNF delivered from the hydrogel upregulates canonical BDNF signaling pathways. The delivery system uses the affinity of BDNF for collagen to control release and increased local BDNF concentrations for at least 3 weeks postimplant (Cook et al., 2017). Additionally, intracranial delivery of the gel to a non-human primate stroke model resulted in sufficient BDNF accumulation in the peri-infarct area (within $1-2 \mathrm{~cm}$ ), a distance relevant for recovery in humans (Nudo et al., 1996; Luft et al., 2004). Interestingly, the drug concentration around the implant varied depending on the direction measured, highlighting the anisotropy of the brain and its effect on diffusion. Importantly, the authors highlight that BDNF only increases the strength of existing connections and cannot overcome growth inhibitors. Thus, BDNF treatment alone may be in insufficient in cases where new connections need to be made, such as when existing connections are insufficient to support adaptive plasticity, or in chronic stroke, where glial inhibition is a significant barrier.

The adult brain ECM and glial cells express many growth inhibitory molecules that limit synaptogenesis and axonogenesis, such as the neurite outgrowth inhibitor (Nogo) (Schwab and Strittmatter, 2014). Inhibiting the activity of these molecules, such as with an anti-NogoA antibody, enhances regeneration, plasticity, and recovery (Buchli and Schwab, 2005). A HA hydrogel was used to deliver a Nogo66 receptor antibody in strokeinjured rats; although increased nerve fiber growth was seen, it was insufficient to produce any significant behavioral recovery (Ma et al., 2007). Combining NogoA inhibition with a growth stimulatory molecule may produce a synergistic effect on axon growth. Controlling the release of anti-NogoA and codelivering it with NT-3 was investigated using a blend of HAMC and PLGA 
particles; increased axon density and improved motor function were achieved in a rat spinal cord injury model (Elliott Donaghue et al., 2016). Perineuronal nets are ECM structures surrounding axon terminals that stabilize synapses in the healthy brain but inhibit new connections in the injured and adult brain (Wang and Fawcett, 2012). ChABC has been found to increase synaptic plasticity by transiently destabilizing these perineuronal nets (Massey et al., 2006). Biomaterial delivery systems have been developed for ChABC (Pakulska et al., 2013), to stimulate recovery in spinal cord injury (Pakulska et al., 2017), and can be applied to existing delivery paradigms in the brain.

\section{CELL DELIVERY}

\section{Goals of Cell Therapy}

As an alternative to drug delivery, many strategies focus on the delivery of an exogenous source of cells to treat stroke. The aim of cell transplantation is to increase the survival of endogenous cells as well as to directly replace damaged tissue to promote regeneration. Cell types used for transplantation to the brain include adult NSCs, mesenchymal stromal cells (MSCs), embryonic stem cell (ESC)- or induced pluripotent stem cell (iPSC)-derived NPCs, and directly reprogrammed induced neural stem cells (Yamashita et al., 2017). Early research also included undifferentiated pluripotent stem cells, however, their use has become limited due to the risk of teratoma and tumor formation (Kawai et al., 2010; Yamashita et al., 2011). Transplanted cells have been demonstrated to promote stroke recovery in animal models through a variety of mechanisms: stimulating both endogenous NPCs and endothelial progenitor cells to migrate to ischemic sites (Bliss et al., 2010; Lindvall and Kokaia, 2011; Dailey et al., 2013), stimulating the proliferation of neuroblasts in the SVZ (Chen et al., 2003; Jin et al., 2011a; Zhang et al., 2011), promoting angiogenesis in the peri-infarct zone (Horie et al., 2011; Zhang et al., 2011; Oki et al., 2012), and decreasing infarct size (Chen et al., 2010a; Gomi et al., 2012; Oki et al., 2012). In addition to the effects on endogenous tissue, transplanted cells can integrate into the existing neural circuitry, reestablishing connections with host cells (Niclis et al., 2017); however, it remains unclear if these new connections contribute directly to recovery.
Although cell transplantation can stimulate stroke recovery in animal models, appreciable long-term survival of cells continues to remain elusive, with an estimated survival of only $2-8 \%$ of the initial transplant population (Nakagomi et al., 2009). This poor survival is attributed to cell death during the transplantation process, lack of endogenous ECM and vasculature in the stroke cavity, lack of prosurvival signals, and low rates of cell differentiation and integration (Modo et al., 2002; Kelly et al., 2004; Hicks et al., 2009). Biomaterials are becoming an important part of the cell delivery paradigm, enhancing the success of cell transplantation through four main strategies, discussed herein, by providing: (1) a platform for in vitro predifferentiation of cells prior to transplantation; (2) a delivery vehicle to reduce acute cell death during the delivery process; (3) a scaffold for cell adhesion and survival after delivery; and (4) a platform for the codelivery of cells and factors to promote cell differentiation and integration (Figure 3). Most biomaterials used for cell transplantation to the brain are hydrogels, and thus will be the focus of this discussion. It is also important to note that many strategies are multifaceted, involving ECM components and proteins that will enhance cell survival, direct differentiation, and/or recruit endogenous cells.

\section{Biomaterials for Cell Therapy}

Early studies of biomaterials for cell transplantation focused on the use of synthetic polymers such as PEG, a highly hydrophilic polymer that is biocompatible and non-immunogenic (Bjugstad et al., 2008; Bhattarai et al., 2010). PEG can be combined with other synthetic polymers, such as PLGA, or with natural polymers. PEG has been used to design hydrogels for cell culture, incorporating FGF2 and type I collagen (Mahoney and Anseth, 2007), or heparin and RGD (Freudenberg et al., 2009) to culture embryonic NSCs, which were both found to increase cell viability. Other synthetic polymers [PGA, PLGA, poly(d-lysine), PCL] are used for a range of applications including: in vitro coating of polycarbonate or plastics [e.g., poly(L-lysine); Jongpaiboonkit et al., 2008], scaffold particles for structural support for cell transplantation (e.g., PLGA; Bible et al., 2009), electrospun nanoparticles (e.g., PCL; Horne et al., 2010), and 3D scaffolds (e.g., PGA; Park et al., 2002). For example, when a PGA 3D scaffold was used to

\begin{tabular}{|c|c|c|c|c|}
\hline & 1. Culture & 2. Injection & 3. Survival & 4. Integration \\
\hline 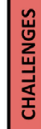 & $\begin{array}{l}\text { - Transfer to } \\
\text { syringe } \\
\text { - Cell survival } \\
\text { - Cell fate }\end{array}$ & $\begin{array}{l}\text { - Dissociation } \\
\text { - Shear stress } \\
\text { - Extensional flow }\end{array}$ & $\begin{array}{l}\text { - Backflow } \\
\text {-Anoikis } \\
\text { - Lack of ECM }\end{array}$ & $\begin{array}{l}\text { - Cell } \\
\text { differentiation } \\
\text {-Axon growth } \\
\text {-Synaptogenesis }\end{array}$ \\
\hline $\begin{array}{l}\sum_{z} \\
\text { 은 } \\
\text { 号 }\end{array}$ & $\begin{array}{l}\text {-Culture in 3D } \\
\text { hydrogels } \\
\text {-Addition of } \\
\text { adhesion peptides }\end{array}$ & $\begin{array}{l}\text { - Shear thinning or } \\
\text { crosslinked } \\
\text { hydrogels }\end{array}$ & $\begin{array}{l}\text { - In situ gelation } \\
\text {-Adhesion peptides } \\
\text {-ECM components }\end{array}$ & $\begin{array}{l}\text {-Integration or } \\
\text { guidance factors } \\
\text { - Topographical } \\
\text { cues }\end{array}$ \\
\hline
\end{tabular}

FIGURE 3 | Biomaterials can be used to address challenges at multiple stages of the cell transplantation paradigm. 1. Biomaterials can be used to prime cells in culture prior to injection to guide cell fate and limit death during transfer to a syringe. 2 . The use of a shear thinning or crosslinked hydrogel can decrease mechanical stress that cells undergo during processing and injection. 3. Biomaterials can aid in cell retention at the injection site and increase cell survival with the addition of adhesion peptides and ECM components. 4. Long-term cell integration can be supported with a biomaterial with factors and topographical cues for cell differentiation, axon guidance, and synapse formation. 
deliver NSCs into the stroke-injured neonatal mouse brain and compared to cell delivery in saline, the scaffold attenuated the immune response, reduced glial scarring, allowed penetration of blood vessels, and promoted differentiation of delivered cells into neurons and glia (Park et al., 2002). While there are advantages to synthetic biomaterials, there are also drawbacks such as biocompatibility issues with many of their acidic degradation products and their inability to interface with native cells and enzymes (Hoffman, 2012).

Natural hydrogels are favored for cell transplantation after stroke due to the similarity in mechanical properties with native brain tissue (i.e., soft consistency and elastic nature) (Table 2). One natural hydrogel used for cell delivery is Matrigel $^{\mathrm{TM}}$, a material derived from a mouse sarcoma cell line primarily composed of laminin-1 and collagen IV and containing many adhesive molecules and growth factors that promote cell viability. Transplantation of mouse ESC-derived NPCs in Matrigel ${ }^{\mathrm{TM}}$ into the striatum resulted in a larger graft volume and increased the number of tyrosine hydroxylase-positive dopaminergic neurons (Uemura et al., 2010). Unfortunately, as Matrigel ${ }^{\mathrm{TM}}$ is derived from a xenobiotic source, it has high batch-to-batch variability and is unsuitable for clinical use (Jin et al., 2010). In addition, Matrigel $^{\mathrm{TM}}$ gels at room temperature through hydrophobic interactions between the components, causing it to be technically challenging for cell injection. To retain the desirable properties of Matrigel $^{\mathrm{TM}}$ without its drawbacks, other strategies have favored the use of ECM-based hydrogels such as HA, fibrin, and collagen as they are well-defined and tunable (Nair and Laurencin, 2007; Nih et al., 2016).

As an alternative to isolating one individual component of the ECM to create a hydrogel, researchers have also derived a multicomponent hydrogel from decellularized natural ECM. Porcine bladder-derived ECM hydrogels promote in vitro $3 \mathrm{D}$ neurite extension (Medberry et al., 2013), and when injected into the cavity of stroke-injured rat brain led to infiltration of neural progenitors and oligodendrocytes into the gel-filled space (Massensini et al., 2015; Ghuman et al., 2016). Natural ECM hydrogels have also been derived from brain and spinal cord, and some have been electrospun with other components for in vitro culture to demonstrate neurite extension (Baiguera et al., 2014; De Waele et al., 2015). One study comparing bladder, spinal cord, and brain ECM reported that there were differences in the chemical composition and mechanical properties between them, and that while all three were able to promote neurite formation, brain ECM promoted the longest and most numerous neurites in a neuroblastoma cell line (Medberry et al., 2013) indicating the superiority of brain-derived ECM for neuronal culture.

TABLE 2 | Naturally-derived biomaterials for cell delivery to the brain.

\begin{tabular}{|c|c|c|c|c|}
\hline Biomaterial & Cell type & Modifications & Outcome & Reference \\
\hline \multirow[t]{2}{*}{$\begin{array}{l}\text { Physical blend of hyaluronan/ } \\
\text { methyl cellulose (HAMC) }\end{array}$} & Adult neural stem/progenitor cells & None & $\begin{array}{l}\text { Behavioral recovery, better cell distribution } \\
\text { within brain compared to saline }\end{array}$ & Ballios et al. (2015) \\
\hline & IPSC-derived neural progenitor cells & & $\begin{array}{l}\text { Cell survival to } 7 \text { days; improved } \\
\text { sensorimotor performance }\end{array}$ & Payne et al. (2017) \\
\hline Matrige| ${ }^{\mathrm{TM}}$ & ESC-derived progenitor cells & None & $\begin{array}{l}\text { Reduction in cavity volume; improved } \\
\text { sensorimotor and cognitive performance }\end{array}$ & Jin et al. (2010) \\
\hline \multirow[t]{3}{*}{ Hyaluronan (HA) } & IPSC-derived progenitor cells & $\begin{array}{l}\text { MMP-degradable or non- } \\
\text { degradable crosslinker }\end{array}$ & $\begin{array}{l}\text { Increased DCX, better cell distribution } \\
\text { with hydrogel; adding MMP-degradable } \\
\text { crosslinker reduced microglial response }\end{array}$ & Lam et al. (2014) \\
\hline & & $\begin{array}{l}\text { BDNF, BMP4, laminin, and/or } \\
\text { fibronectin }\end{array}$ & $\begin{array}{l}\text { Growth factors promoted astrocytic } \\
\text { differentiation; adhesion proteins promoted } \\
\text { neuronal differentiation }\end{array}$ & Moshayedi et al. (2016) \\
\hline & Primary rodent NPCs & Crosslinked with heparin & $\begin{array}{l}\text { Increased cell survival; decreased } \\
\text { microglial response compared to } \\
\text { cells alone }\end{array}$ & Zhong et al. (2010) \\
\hline Collagen & ESC-derived neural stem cells & Laminin or fibronectin & $\begin{array}{l}\text { Collagen I gel with laminin improved cell } \\
\text { survival a behavioral recovery over untreated } \\
\text { group }\end{array}$ & Tate et al. (2009) \\
\hline \multirow[t]{2}{*}{ Fibrin } & iPSC-derived NPCs & None & $\begin{array}{l}\text { Fibrin glue + cells reduced infarct volume, } \\
\text { promoted functional recovery }\end{array}$ & Chen et al. (2010a) \\
\hline & & & $\begin{array}{l}\text { Reduced infarct volume, inflammation and } \\
\text { gliosis; increased recovery, angiogenesis } \\
\text { and white matter tract integrity }\end{array}$ & Lee et al. (2017) \\
\hline \multirow[t]{2}{*}{ Self-assembling peptides } & Primary rodent NSCs & IKVAV peptide & $\begin{array}{l}\text { RADA peptide hydrogel with and without } \\
\text { IKVAV; enhanced cell survival and neuronal } \\
\text { marker expression }\end{array}$ & Cheng et al. (2013) \\
\hline & Human iPSC-derived NPCs & IKVAV peptide & $\begin{array}{l}\text { Reduced brain atrophy, long-term } \\
\text { functional recovery, and neuronal } \\
\text { differentiation }\end{array}$ & Somaa et al. (2017) \\
\hline
\end{tabular}




\section{In Vitro Cell Priming}

Biomaterials can be used to culture cells prior to transplantation, enhancing the success of cell therapies. It has been demonstrated that priming cells in vitro through a variety of mechanismsguiding differentiation, stimulating the secretion of factors, or exposing cells to stressful conditions-can increase their therapeutic efficacy once delivered to the brain (Rosenblum et al., 2015; Lee et al., 2017). It has also been suggested that predifferentiating pluripotent or multipotent cells toward a neuronal lineage prior to transplantation can increase tissue and behavioral recovery (Fricker-Gates et al., 2002; Tornero et al., 2013). Culturing adult and embryonic NPCs in 3D HA hydrogels can promote differentiation and enhance neurite outgrowth and synapse formation (Ma et al., 2004; Hou et al., 2005; Khaing and Seidlits, 2015). The addition of factors into HA hydrogels can enhance the desired priming effects. For example, a design of experiment approach was used by Lam et al. to optimize the concentration of adhesive peptides-RGD, IKVAV, and YIGSR-on HA hydrogels for 3D NPC survival and differentiation (Lam et al., 2015). The authors determined that the optimal concentration of each peptide was not the often used 1:1:1 ratio, and that strategic optimization of each factor concentration can lead to enhanced survival and neurite length. Another study combined both RGD and heparin components within a HA hydrogel using click chemistry to culture hPSC-derived NPCs and differentiate them into midbrain dopaminergic neurons for transplantation (Adil et al., 2017). The use of both factors increased cell differentiation, neurite extension, and resulted in functional neurons that could fire action potentials in vitro. When transplanted into the rat striatum these cells showed a fivefold increase in cell number compared to unencapsulated controls. Lastly, in an approach targeting cell migration, Addington et al. (2015) aimed to enhance the NSC response to in vivo SDF- $1 \alpha$ gradients by priming the cells in culture with HA-laminin hydrogels. The authors reported that culturing NSPCs in these gels resulted in an increased response to SDF-1 $\alpha$ gradients in vitro, with increased CXCR4 receptor expression after $48 \mathrm{~h}$ of culture that was dependent on the concentration of HA and laminin used. In a follow-up study, the researchers transplanted HA-laminin-primed NSPCs into intact mouse brains and reported an increase in cell migration out of the transplantation site that was dependent on the SDF-1 $\alpha /$ CXCR4 interaction (Addington et al., 2017).

\section{Improving Cell Delivery}

The majority of intracerebral cell delivery strategies are syringebased. Necessary steps in the transplantation paradigm, such as preparation of cells for transfer from culture into a syringe, and injection of cells into the brain, can result in a substantial amount of cell death (Rossetti et al., 2016; Payne et al., 2017). Small-bore needles are favored for cell delivery as they are minimally-invasive for the host tissue; however, they increase the mechanical disruption and shear stress that cells experience during injection (Rossetti et al., 2016). Other variables such as time between preparation and implantation of cells, concentration of cells, needle length, rate of injection, and suspension medium all impact the survival of cells (Heng et al., 2009; Amer et al., 2015; Rossetti et al., 2016). Although not often reported, this acute loss of cells can impact the therapeutic success of cell transplantation at the onset of delivery.

The ability of biomaterials to reduce acute cell death has been tested using several hydrogel systems. The extensional shear stress that cells experience as they pass through the comparatively large diameter syringe into the smaller diameter needle can be reduced by encapsulation in a biomaterial. Amer et al. (2015) investigated the effect of the vehicle during injection on fibroblast viability using crosslinked or non-crosslinked alginate gels, as well as a high viscosity carboxymethylcellulose solution, and determined that only the crosslinked alginate hydrogel significantly increased acute viability of cells. It has been suggested that crosslinked hydrogels can undergo plug flow where the hydrogel at the interface of the syringe and needle will undergo shear thinning and this acts as a lubricant to the inner core of the gel, thus reducing the shear stress and extensional forces experienced by the cells. A crosslinked alginate hydrogel also increased viability of human umbilical vein endothelial cells and mouse NPCs immediately after injection, from $59 \%$ survival in saline to $89 \%$ in the hydrogel (Aguado et al., 2011); however, the authors did not test the hydrogel for long-term cell culture or in vivo viability, which could be impacted by the hydrogel crosslinking, which determines the elastic modulus and the gel stiffness (Banerjee et al., 2009). HA also promotes iPSC-NPC viability when high concentrations of cells (i.e., $60-90 \mathrm{k}$ cells $/ \mu \mathrm{L}$ ) were injected through a needle of 28-gage or higher compared to a buffer solution (Lam et al., 2014). Interestingly, viability can vary depending on the susceptibility of the specific cell type to damage. For example, a mature neuronal phenotype experiences more cell death with the use of a HA-MC gel than less-differentiated NPCs (Payne et al., 2017).

A single scaffold can be used to first culture and then deliver cells into the brain, avoiding cell death due to dissociation and supporting cell survival and function both pre- and postinjection. Electrospun synthetic poly(desaminotyrosyl tyrosine ethyl ester carbonate) microfibers were used to accelerate the differentiation of human iPSCs into induced neuronal cells in vitro (Carlson et al., 2016). Cells grown and differentiated on these fibers and transplanted into the mouse striatum survived better than dissociated cells alone. In an interesting approach, the Cullen lab devised micro-tissue engineered neural networks (microTENNs) to deliver preformed networks of axonal tracts both with and without astrocyte support (Struzyna et al., 2015; Winter et al., 2016). These constructs consist of an outer columnar agarose shell that is filled with an ECM hydrogel, such as collagen or laminin. Cells are then either seeded at one end of the tube where they extend neurites through the construct, or are dispersed along the length of the construct and cultured to create a neural network that can then be transplanted directly into the brain. In addition, once formed, the neural network can be removed still intact from the construct for further culture or immunochemical analysis. Micro-TENNS can be inserted directly without the use of a needle into the brain and, in naive rats, resulted in cell survival for up to 1 month, maintenance of an axonal network, and shortdistance integration into the host tissue (Struzyna et al., 2015). Coculturing neurons along astrocyte networks within collagen hydrogel micro-columns resulted in neurites that extended along the astrocytic bundles, mimicking the glial tube of the rostral 
migratory stream that guides neuroblasts in vivo (Winter et al., 2016). Although promising, one potential issue with these constructs is scaling up for humans; it is unclear how much larger the scaffolds would need to be to traverse damaged areas in the human brain, and whether this would affect insertability and cell viability. In addition, material degradation and cytocompatibility of bioresorption products require further investigation.

\section{Increasing Cell Retention and Survival Cell Retention}

Although cell delivery can be achieved via intravascular or intracerebroventricular delivery, the preferred route is directly into the stroke site (Jin et al., 2005; Bliss et al., 2010). The infarct provides a convenient space for delivery of a relatively large volume of cells, avoiding damage to nearby intact tissue while also localizing cells to the potentially salvageable tissue in the peri-infarct (Zhong et al., 2010; Willing and Shahaduzzaman, 2013; Ballios et al., 2015). Smith et al. compared cell transplantation to the intracerebroventricular or intraparenchymal peri-infarct locations and after 14 weeks only found surviving cells when delivered into the intraparenchymal peri-infarct (Smith et al., 2012). However, the advantages of injection into the infarct also come with obstacles: there is a lack of ECM and vasculature to retain cells at the site of injection and support survival, the presence of proapoptotic signals from surrounding cells, and immune cell infiltration (Modo et al., 2002; Kelly et al., 2004; Hicks et al., 2009). Biomaterials can provide a scaffold to fill the stroke cavity, providing a substrate for cell adhesion and aiding in cell distribution and retention at the injection site to prevent washout into the CSF.

Cell retention immediately after injection into the brain is important for long-term cell survival and functional recovery. If injected in a saline solution, cells can backflow out of the brain tissue through the needle tract made by the injection (Ballios et al., 2015). A hydrogel system that can gel in situ is ideal as it provides an injectable material that becomes more viscous once in the brain and retains cells at the infarct site. Studies directly comparing cell transplantation with and without a hydrogel carrier have reported a higher number of cells in the brain immediately following injection with the use of a hydrogel (Ballios et al., 2015; Cai et al., 2015), which is attributed to increased cell retention. HAMC, which is shear-thinning and inverse-thermal gelling, allows cells to be injected through a fine-gage needle into the brain where it will gel to localize cells to the injury site (Ballios et al., 2015; Payne et al., 2017). HAMC provides superior cell distribution and larger maximal depth in the infarct area, which correlates to improved functional recovery compared to saline (Ballios et al., 2015). In a different approach, Cai et al. developed a dual crosslinking hydrogel system, termed SHIELD, composed of a star-PEG copolymer and a recombinant peptide sequence (Cai et al., 2015). The components of SHIELD form a weak physical network prior to delivery in order to protect cells as they pass through the syringe, then undergoes a second crosslinking in situ by thermal phase transition of the recombinant protein to increase the percentage of cells retained postinjection. While only tested with adipose-derived stem cells transplanted subcutaneously, this biomaterial system may enhance cell survival and retention in other tissues.

\section{Cell Survival}

Transplantation of cells directly into the stroke cavity often leads to widespread cell death, attributable in part to anoikis (i.e., lack of adhesion cues) (Jen et al., 1996; Hersel et al., 2003). The addition of ECM components to a cell delivery vehicle can mimic the native ECM, providing adhesion cues to transplanted cells and increasing the success of transplantation. An alternative to full-length protein immobilization is the use of short synthetic peptide sequences, which are advantageous because they are more stable than proteins and thus less susceptible to degradation, are easier and less costly to synthesize, and can target one particular molecular pathway in the cell, unlike proteins that often have different functional domains that may elicit unwanted responses (Hersel et al., 2003; Cooke et al., 2010). NSCs express many integrins that allow them to interact with ECM proteins, such as $\beta 1$-integrin, which binds to the IKVAV sequence of laminin and promotes neuronal differentiation (Pan et al., 2014). During development many integrins are expressed on NSCs in a temporal fashion as they differentiate, which should be taken into account when designing a hydrogel with adhesion molecules (Milner and Campbell, 2002; Wojcik-Stanaszek et al., 2011). The developmental stage from which NSCs are derived can also determine which integrins are expressed, affecting the binding ability of cells to ECM ligands. For example, of mouse NSPCs derived from embryonic, early postnatal or adult SVZ, only postnatal-derived NSPCs adhered to a collagen I hydrogel (Bergström et al., 2014).

Notwithstanding other common adhesive ligands, laminin and the laminin-derived peptide IKVAV have been used successfully for cell delivery to the brain (Stabenfeldt et al., 2006; Cheng et al., 2013; Somaa et al., 2017). NPCs express the major integrin for laminin, $\alpha 6 \beta 1$, which promotes differentiation of hESCs to neurons in vitro (Ma et al., 2008; Stabenfeldt et al., 2010). When collagen I hydrogels containing fibronectin or laminin were compared for delivery of fetal-derived NSCs, laminin-containing gels resulted in increased cell survival 8 weeks posttransplantation compared to those with fibronectin (Tate et al., 2009). The authors do not offer a mechanism for the superior performance of laminin over fibronectin, but laminin may promote neuronal differentiation and neurite extension (Ma et al., 2008; Li et al., 2014). Another study which used a self-assembling peptide (SAP) hydrogel of repeating RADA amino acid units with IKVAV enhanced survival of rat NSCs in vitro compared to an SAP hydrogel without IKVAV, and improved survival of NSCs and expression of neuronal markers 6 weeks after transplantation into a rat TBI model (Cheng et al., 2013). Using a similar SAP IKVAV hydrogel, human NPCs transplanted into a rat stroke model reduced brain atrophy and improved recovery of motor function up to 9 months posttransplantation while enhancing neuronal differentiation (Somaa et al., 2017) (Figure 4).

\section{Promoting Cell Differentiation and Integration}

Once cells are delivered to the site of injury, they must not only survive long enough to be therapeutically efficacious, but also differentiate and integrate into the host tissue to promote sustained functional recovery. It has been reported that when 

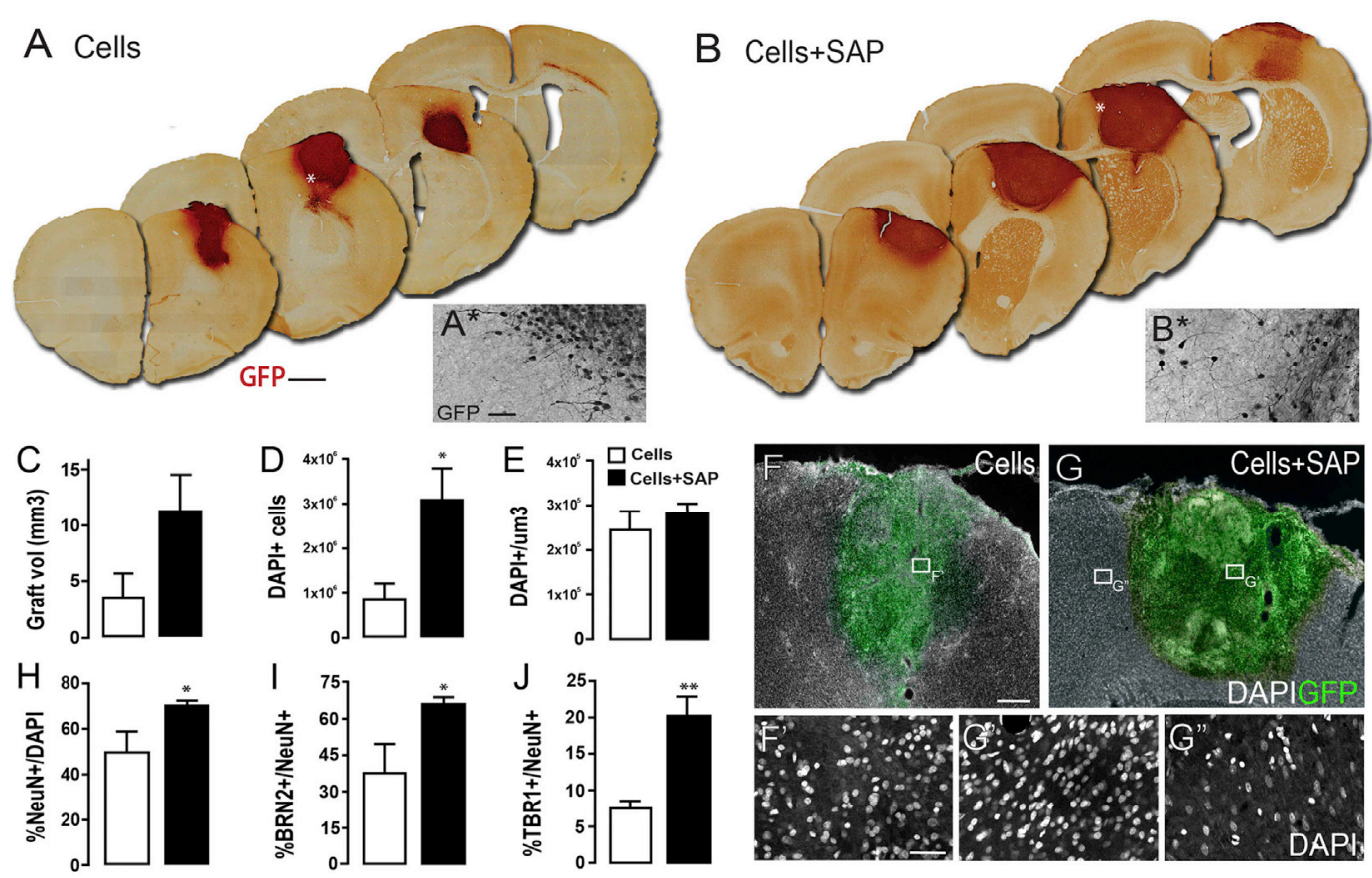

FIGURE 4 | Human neural progenitor cells (hNPCs) encapsulated in a self-assembling peptide (SAP) hydrogel and delivered into a stroke-injured rat brain demonstrate increased cell survival and differentiation into neurons. Representative coronal brain sections containing (A) cells or (B) cells + SAP. (C) Graft volume. (D) Number and (E) density of hNPCs detected in each group. (F-G) Representative images of (F) transplanted cells alone or (G) in combination with SAP hydrogel. (H-J) Percentage of hNPCs expressing neuronal markers. Reproduced with permission from Somaa et al. (2017).

undifferentiated NSCs are transplanted into the stroke-injured brain, they often differentiate into astrocytes over neurons (Dziewczapolski et al., 2003; Abeysinghe et al., 2015; Ballios et al., 2015), which may contribute to the glial scar. Therefore, if the goal is neuronal replacement, it is desirable to control the cell fate after injection with the delivery system.

The properties of the biomaterial alone can influence neural cell fate. For example, ventral midbrain-derived NPCs will differentiate into neurons when the mechanical properties of an HA hydrogel match that of the neonatal brain (Seidlits et al., 2010). Proliferation of NSCs can be controlled by changing the modulus of 3D alginate hydrogels, with stiffer gels causing a reduction in proliferation and $\beta$ III-tubulin expression (Banerjee et al., 2009). The differentiation of cells cultured on fibrous scaffolds can be controlled by tuning the thickness of the fibers; rat NSCs cultured on polyethersulfone fiber meshes differentiate preferentially into oligodendrocytes on smaller diameter fibers and into neurons on wider diameter fibers (Christopherson et al., 2009). Others have seen an increase in NSC differentiation in vivo with the use of HA hydrogels (Lam et al., 2014; Führmann et al., 2016; Moshayedi et al., 2016).

\section{Differentiation of Transplanted Cells}

In addition to acting as a physical scaffold, biomaterials can be combined with factors to help promote the integration of transplanted cells by guiding axon growth and synapse formation, and/or stimulating the differentiation of delivered cells into the desired phenotype. As biomaterials allow the controlled release of factors for sustained availability to transplanted cells, they can be used to deliver cells concurrently with factors to both support initial survival of cells and promote later differentiation. Many factors can control cell fate, yet few have been tested in combination with cell delivery in a hydrogel delivery system for stroke. Moshayedi et al. (2016) encapsulated hiPSC-derived NPCs in HA gels modified with MMP-cleavable sequences for degradation in the brain, as well as soluble factors, BDNF and BMP4, and adhesive laminin peptides, YIGSR and IKVAV (Moshayedi et al., 2016). The authors found that after injection of the hydrogel with cells into the stroke-injured mouse brain, BDNF and BMP4 promoted astrocytic differentiation whereas the laminin sequences promoted neuronal differentiation. Other studies have used synthetic microparticles to release growth factors in conjunction with cell delivery, albeit with mixed results. One study used PLGA microparticles coated with laminin and containing encapsulated VEGF to deliver MSCs that were adhered to the particle surface (Quittet et al., 2015). The authors reported that MSC transdifferentiated into neurons due to the presence of laminin, recruited blood vessels to the site, and increased the number of endogenous DCX-positive cells in the infarct. Despite the beneficial tissue effects, the authors did not report functional recovery in a battery of behavioral tests and suggested that this could have been the result of an unanticipated delay in VEGF release in vivo, such that an insufficient amount of VEGF was released during the therapeutic window. Another study combined BDNF-releasing PLGA microparticles, coated with fibronectin, seeded with MSC-like cells on the surface, and all blended into 
a silanized-hydroxypropyl MC hydrogel (Kandalam et al., 2017). The authors found that this combination promoted neural differentiation of the cells as well as upregulated the secretion of beneficial growth factors and chemokines, but did not test cell viability. A study which implanted VEGF-releasing PLGA microparticles with human NSCs into the brain saw neovascularization within the infarct site, but also a large amount of immune cell infiltration and decreased transplanted cell viability over time (Bible et al., 2012). The authors suggested that the increased cell death may have been a result of the degradation of the PLGA into acidic byproducts. Indeed, a significantly higher concentration of PLGA was used in their formulation compared to the previously described studies, as well as a different cell type (NSC vs. MSC), suggesting that the concentration of PLGA requires optimization for cell viability. Although multicomponent strategies such as these can target multiple repair pathways, it remains a challenge to gain mechanistic insight into recovery without the many required controls. In many cases, although the effect of a factor alone is known, the synergistic interactions between two or more factors are not. Further work needs to be done to identify promising combinations to augment cell delivery while elucidating the mechanism behind recovery.

\section{Axon Guidance and Synapse Formation}

The ability of delivered cells to form connections with the host neurons, functionally integrating into the established circuitry, is a crucial step for successful cell replacement therapy (Ishibashi et al., 2004; Tornero et al., 2017). Without the appropriate stimuli, such as topographical or chemical cues, transplanted cells may not form these functional connections. Biomaterials have been used extensively to provide topographical cues to cells in vitro and in spinal cord injury models, but this is a newly emerging strategy for in vivo stroke models (Béduer et al., 2012; Nih et al., 2016; Tarus et al., 2016). A pioneering study engineered a micropatterned solid polydimethylsilosane (PDMS) scaffold containing microchannels and seeded with neurons for implantation into the rat brain. The authors reported significant motor recovery and increased cell survival 3 weeks after implantation compared to the sham animals (Vaysse et al., 2015). In a follow-up publication, the host response to the scaffold was analyzed: there was no significant increase in activated ED1-positive microglia at the implant site and surprisingly a decrease in the astrogliosis response compared to the sham (Davoust et al., 2017), suggesting that the implant is well tolerated long-term. Future studies could also focus on combining topographical cues with some of the factors discussed in previous sections known to promote connectivity and plasticity in the brain (Wei et al., 2007; Bliss et al., 2010).

\section{OUTLOOK}

\section{Improving Biomaterial Design}

Biomaterials have been successfully used as delivery vehicles for drug and cell therapeutics to the brain. Many of the materials discussed meet necessary design criteria (biocompatibility, minimally swelling, injectable, shape adaptable, and biodegradable/ bioresorbable). However, there has been limited exploration of the material itself as a therapeutic. Advances in material design that have been implemented in other tissue systems, such as modifications to material porosity, topography and mechanical cues to control the cellular response to the biomaterial, can be adapted for brain repair. Only recently has porosity been explored in the context of brain repair; a micro-porous HA hydrogel, injected into the stroke cavity, demonstrated that porosity can be used to achieve superior cellular infiltration and attenuation of the inflammatory response compared to non-porous hydrogels (Nih et al., 2017). Future work may include optimizing the pore size of a material for the desired cellular response, such as for neurogenesis, axonogenesis or vasculogenesis. In addition, surface functionalization, such as peptide modification, can be combined with a porous hydrogel to mimic cell-cell interactions at the biomaterial-cell interface, which has been demonstrated to control stem cell differentiation (Stabenfeldt et al., 2006; Tate et al., 2009; Li et al., 2014). While the mechanical and chemical properties of a biomaterial are typically linked, new synthetic strategies will allow the ECM ligand concentration to be decoupled from the hydrogel crosslink density, thereby resulting in materials with independently tunable mechanical and chemical properties (Fisher et al., 2015). Computational advancements and machine learning will allow us to use predictive modeling to explore and optimize multiple biomaterial parameters (e.g., elasticity, porosity, composition) simultaneously, enabling improvements in existing materials and the development of novel materials (Vasilevich et al., 2017).

\section{Biomaterials in Novel Treatments}

Biomaterials will enable sustained delivery of novel treatments. The direct reprogramming of astrocytes in the glial scar into proliferative neuroblasts has been proposed as a feasible method of reducing the glial scar, and generating neuron and oligodendrocyte precursors at the site of injury and repair, even in aged brains (Niu et al., 2013; Guo et al., 2014b). This can be achieved through retroviral or lentiviral transfection of $\mathrm{GFAP}^{+}$astrocytes to express reprogramming factors NeuroD1 or Sox2. However, low transfection efficiency and concerns of diffuse non-specific targeting hinder this approach ( $\mathrm{Li}$ et al., 2016). Biomaterials can be used to address these concerns by sequestering viral particles, increasing local concentrations of the vector and extending the length of virus activity to increase transfection efficiency of infiltrating cells. Retaining the viral particles within the gel limits transfection to cells at the boundary and to infiltrating cells, controlling reprogramming to cells solely within the glial scar-bounded infarct and reducing diffuse non-specific exposure (Shin and Shea, 2010; Seidlits et al., 2013). Recent developments have found that cocktails of small molecules can achieve the same reprogramming as viral vectors, without xenobiotic concerns, in astroglial cells (Zhang et al., 2015) and fibroblasts (Hu et al., 2015; Li et al., 2015). Indeed, a few innovative researchers have begun incorporating these factors into nanoparticles to reprogram astrocytes into neurons and oligodendrocytes (Li et al., 2016, 2017). Many of the discussed advancements in local delivery of therapeutic factors are directly applicable to local and controlled delivery of reprogramming molecules. 
The ability of neurons to be stimulated by electrical fields has been explored as a novel strategy to promote both cell migration and differentiation. Stimulating cell migration takes advantage of the galvanotaxis demonstrated by NSPCs (Babona-Pilipos et al., 2011), whereby neurons migrate in response to an applied electric field. This approach has been proposed for in vivo use through externally applied electric fields to increase and direct the migration of endogenous NSPCs, though it could also be used to direct the migration of transplanted stem cells to prevent their clustering (Iwasa et al., 2017). Recent advances in electrically conductive materials may aid in scaling this approach to larger human brains where sufficient electrical fields may be difficult to generate or more spatially defined electrical fields may be desired (Zhou et al., 2017).

In addition to influencing cell migration, electrical stimulation of ESCs can bias their fate toward neuronal differentiation via changes in calcium influx (Yamada et al., 2007; Pires et al., 2015). Graphene is a biocompatible material with good electrical conductivity that allows electrical cues to be introduced to the cells to promote differentiation and connectivity (Gardin et al., 2016). Various forms of graphene can be used for neural cell culture, increasing differentiation of NSCs into neurons or oligodendrocytes (Menaa et al., 2015), and it can be utilized to differentiate cells in vitro prior to transplantation (Heo et al., 2011). An interesting study combined graphene in the form of single-walled carbon nanotubes with laminin to culture NSCs, which were then stimulated by an electrical current, generating action potentials and forming a neural network (Chao et al., 2009). Graphene has shown promise in vitro but the in vivo biocompatibility and tolerance remains unknown. Implantation of electrically preconditioned cells was recently demonstrated using a conductive polymer scaffold where Human neural progenitor cells (hNPCs) cultured on a polypyrrole scaffold and exposed to electrical stimulation upregulated genes in the VEGF-A pathway (George et al., 2017). When cells on these scaffolds were stimulated and transplanted onto the cortical surface of stroke-injured rats they elicited functional improvement in multiple behavioral tasks and increased the peri-infarct vasculature in a VEGF-dependent manner compared to unconditioned cells; however, no surviving cells were detected at two weeks posttransplantation. Future work combining electrical stimulation and cell delivery may lead to further advances in the in vivo control of stem cell fate.

\section{Improving Clinical Translation}

Advances in biomaterials and tissue engineering improve therapies that aim to protect and repair the brain, serving as vehicles for drug and cell delivery, and scaffolds for tissue regeneration that integrate with the host tissue. However, it remains a nascent field and successful clinical translation will require learning from the failures of previous neuroprotective efforts (O'Collins et al., 2006). Many preclinical studies with biomaterials have demonstrated a limited number of tissue-specific outcomes without providing evidence for behavioral recovery. Though the lack of behavioral recovery does not undermine the value of a study, landmark studies will require robust demonstration of functional outcomes in multiple tests. Another major hurdle is the lack of a consistent set of clinically relevant goals and study designs. Most preclinical studies limit testing to a single stroke model in young animals with homogeneous etiologies, yet the majority of clinical cases occur in an older population with heterogeneous etiologies (Savitz et al., 2011). Thus, conclusions drawn from preclinical studies using a single model may not be robust enough for the heterogeneous etiologies seen clinically, and studies exclusively on young animals are not reflective of the stroke demographic. As one set of studies demonstrated, aged animals have a lessrobust capacity for plasticity and require modifications to their treatment to achieve the same outcome found in young animals (Clarkson et al., 2015). Future studies should also incorporate the guidelines set forward by Stroke Therapy Academic Industry Round Table (STAiRS) for preclinical studies in order to build a knowledge base for the field that has practical translation aspects [Stroke Therapy Academic Industry Roundtable (STAIR), 1999; Saver et al., 2009]. Along with appropriate study design, the choice of biomaterial and any chemical modifications should be carefully considered. In addition to the basic requirements discussed herein, the biomaterial must be easily sterilized and manufactured, and any chemistry involved in manufacturing the material should be reproducible, scalable and cost-effective.

Biomaterial delivery can be improved by combining it with in vivo imaging. One often overlooked fact is that while human strokes vary in their size and location, preclinical studies often assume a fixed infarct volume and use a fixed volume of hydrogel. To address this, the Modo group used magnetic resonance imaging (MRI) to measure the individual infarct volume in each animal, in order to adjust the volume of hydrogel delivered and to guide injections to the precise site of injury (Massensini et al., 2015). The group also employed a drainage catheter to remove any fluid buildup in the cavity, displacing it for the injected hydrogel to provide better hydrogel retention and reduce backflow. MRI can also be used to track the biomaterial implant over time, ensuring accurate material implantation, sufficient stability, and adequate degradation for newly formed tissue (Cook et al., 2017). These strategies can improve the delivery and tracking of biomaterials in the brain, increasing both the success of the treatment and its relevance to clinical applications.

Brain repair is a multifaceted process; achieving functional repair with biomaterial-based therapies may require combination with other treatment modalities, such as rehabilitation or transcranial magnetic stimulation (TMS), in order to target multiple repair pathways (Wieloch and Nikolich, 2006). Regenerated or reestablished neural circuitry, if not directed by an appropriate stimulus, can result in uncontrolled plasticity and/or aberrant connections (Murphy and Corbett, 2009). Rehabilitation may enhance functional integration and wiring of newly generated or transplanted neurons (Winstein et al., 2016). Targeting the desired neural pathways with specific rehabilitative tasks simultaneously with delivered cells or drugs may stimulate the reestablishment of appropriate functional connections and discourage the formation of aberrant ones; this was demonstrated with the use of ChABC to produce task-specific recovery (Soleman et al., 2012). Furthermore, recovery of fine motor skills appears to be dependent on receiving the proper type of training; animals that received training in gross locomotor skills performed worse in fine motor tasks than those which received no treatment 
(García-Alías et al., 2009). Thus, functional outcomes with reparative therapies may require appropriate rehabilitation to guide plasticity and rewiring. The reduced plasticity exhibited in chronic injuries and aged patients may make functional integration difficult, even if combined with rehabilitation. Direct brain stimulation with TMS has been used to stimulate brain regions for stroke recovery (Takeuchi et al., 2005; Khedr et al., 2010) and enhance BDNF-mediated plasticity (Wang et al., 2011a). TMS has also been shown to increase the proliferation of resident adult NSCs in the SVZ though the miR-25/p57 pathway (Guo et al., 2014a). While TMS may be combined with delivery of cells or stimulation of endogenous cells, research has shown that the intensity of TMS must be finely tuned or it can negatively impact cell survival (Beom et al., 2015; Kremer et al., 2016), suggesting that more work needs to be done before this strategy can be combined successfully. Nonetheless, using a combinatorial therapy of biomaterials, drug and/or cells, and rehabilitation or TMS, may provide the synergistic approach required to achieve recovery in chronic injuries and aged patients.

\section{Conclusion}

Stroke is a devastating event that manifests as a complex, multicellular injury with limited ability for self-repair. By combining drug and cell delivery strategies with biomaterial solutions, we can enhance the efficacy of treatments to promote regeneration. Although the architecture and morphology of the brain impose a unique set of constraints on biomaterial design, innovative research provides superior drug and cell delivery to the brain with a wide-range of

\section{REFERENCES}

Abeysinghe, H. C. S., Bokhari, L., Quigley, A., Choolani, M., Chan, J., Dusting, G. J., et al. (2015). Pre-differentiation of human neural stem cells into GABAergic neurons prior to transplant results in greater repopulation of the damaged brain and accelerates functional recovery after transient ischemic stroke. Stem Cell Res Ther. 6, 1-19. doi:10.1186/s13287-015-0175-1

Addington, C.P., Dharmawaj,S., Heffernan,J. M.,Sirianni, R.W., andStabenfeldt, S.E. (2017). Hyaluronic acid-laminin hydrogels increase neural stem cell transplant retention and migratory response to SDF-1 $\alpha$. Matrix Biol. 6, 206-216. doi:10.1016/j.matbio.2016.09.007

Addington, C. P., Heffernan, J. M., Millar-Haskell, C. S., Tucker, E. W., Sirianni, R. W., and Stabenfeldt, S. E. (2015). Enhancing neural stem cell response to SDF-1 $\alpha$ gradients through hyaluronic acid-laminin hydrogels. Biomaterials 72, 11-19. doi:10.1016/j.biomaterials.2015.08.041

Adil, M. M., Vazin, T., Ananthanarayanan, B., Rodrigues, G. M. C., Rao, A. T., Kulkarni, R. U., et al. (2017). Engineered hydrogels increase the post-transplantation survival of encapsulated hESC-derived midbrain dopaminergic neurons. Biomaterials 136, 1-11. doi:10.1016/j.biomaterials.2017.05.008

Agnihotri, S. A., Mallikarjuna, N. N., and Aminabhavi, T. M. (2004). Recent advances on chitosan-based micro- and nanoparticles in drug delivery. J. Control Release 100, 5-28. doi:10.1016/j.jconrel.2004.08.010

Aguado, B. A., Mulyasasmita, W., Su, J., Lampe, K. J., and Heilshorn, S. C. (2011). Improving viability of stem cells during syringe needle flow through the design of hydrogel cell carriers. Tissue Eng. A 18, 806-815. doi:10.1089/ten. tea.2011.0391

Amer, M. H., White, L. J., and Shakesheff, K. M. (2015). The effect of injection using narrow-bore needles on mammalian cells: administration and formulation considerations for cell therapies. J. Pharm. Pharmacol. 67, 640-650. doi:10.1111/ jphp. 12362

Arvidsson, A., Collin, T., Kirik, D., Kokaia, Z., and Lindvall, O. (2002). Neuronal replacement from endogenous precursors in the adult brain after stroke. Nat. Med. 8, 963-970. doi:10.1038/nm747 materials, from controlled release of multiple drugs to promote endogenous regeneration, to increased survival and differentiation of delivered cells. While the field has enjoyed preclinical success, several hurdles must be overcome for clinical translation. Some of these can be addressed with the use of consistent guidelines for material design, as well as methodological improvements to the delivery of the biomaterial. The use of a combinatorial strategycombining the delivery with cells or other factors, or drugs/cells with other interventions such as rehabilitation-may provide the multipronged approach needed for regeneration and recovery. Previously failed preclinical strategies may be resurrected through combination with biomaterials, especially if the reason for failure was off-target effects or inability to cross the BBB. Future biomaterial development should be tailored to advancements in preclinical and clinical knowledge of stroke repair treatment modalities.

\section{AUTHOR CONTRIBUTIONS}

AT, SP, and MS contributed to the writing and editing of this manuscript.

\section{FUNDING}

We are grateful to funding from the Natural Sciences and Engineering Research Council, the Canadian Institutes of Health Research, and the Canada First Research Excellence Fund to Medicine by Design. We thank members of the Shoichet lab for thoughtful discussion and input.

Austin, J. W., Kang, C. E., Baumann, M. D., DiDiodato, L., Satkunendrarajah, K. Wilson, J. R., et al. (2012). The effects of intrathecal injection of a hyaluronan-based hydrogel on inflammation, scarring and neurobehavioural outcomes in a rat model of severe spinal cord injury associated with arachnoiditis. Biomaterials 33, 4555-4564. doi:10.1016/j.biomaterials.2012. 03.022

Babona-Pilipos, R., Droujinine, I. A., Popovic, M. R., and Morshead, C. M. (2011). Adult subependymal neural precursors, but not differentiated cells, undergo rapid cathodal migration in the presence of direct current electric fields. PLoS ONE 6:e23808. doi:10.1371/journal.pone.0023808

Baeten, K. M., and Akassoglou, K. (2011). Extracellular matrix and matrix receptors in blood-brain barrier formation and stroke. Dev. Neurobiol. 71, 1018-1039. doi:10.1002/dneu.20954

Baiguera, S., Del Gaudio, C., Lucatelli, E., Kuevda, E., Boieri, M., Mazzanti, B., et al. (2014). Electrospun gelatin scaffolds incorporating rat decellularized brain extracellular matrix for neural tissue engineering. Biomaterials 35, 1205-1214. doi:10.1016/j.biomaterials.2013.10.060

Ballabh, P. P., Braun, A. A., and Nedergaard, M. M. (2004). The blood-brain barrier: an overview - structure, regulation, and clinical implications. Neurobiol. Dis. 16, 13-13. doi:10.1016/j.nbd.2003.12.016

Ballios, B. G., Cooke, M. J., Donaldson, L., Coles, B. L. K., Morshead, C. M., van der Kooy, D., et al. (2015). A Hyaluronan-based injectable hydrogel improves the survival and integration of stem cell progeny following transplantation. Stem Cell Reports 4, 1031-1045. doi:10.1016/j.stemcr.2015.04.008

Banerjee, A., Arha, M., Choudhary, S., Ashton, R. S., Bhatia, S. R., Schaffer, D. V., et al. (2009). The influence of hydrogel modulus on the proliferation and differentiation of encapsulated neural stem cells. Biomaterials 30, 4695-4699. doi:10.1016/j.biomaterials.2009.05.050

Barkho, B. Z., Munoz, A. E., Li, X., Li, L., Cunningham, L. A., and Zhao, X (2008). Endogenous matrix metalloproteinase (MMP)-3 and MMP-9 promote the differentiation and migration of adult neural progenitor cells in response to chemokines. Stem Cells 26, 3139-3149. doi:10.1634/stemcells. 2008-0519 
Barkho, B. Z., and Zhao, X. (2011). Adult neural stem cells: response to stroke injury and potential for therapeutic applications. Curr. Stem Cell Res. Ther. 6, 327-338. doi:10.2174/157488811797904362

Barreto, G. E., Gonzalez, J., Torres, Y., and Morales, L. (2011). Astrocytic-neuronal crosstalk: implications for neuroprotection from brain injury. Neurosci. Res. 71, 107-113. doi:10.1016/j.neures.2011.06.004

Bedard, A., and Parent, A. (2004). Evidence of newly generated neurons in the human olfactory bulb. Brain Res. Dev. Brain Res. 151, 159-168. doi:10.1016/j. devbrainres.2004.03.021

Béduer, A., Vieu, C., Arnauduc, F., Sol, J.-C., Loubinoux, I., and Vaysse, L. (2012). Engineering of adult human neural stem cells differentiation through surface micropatterning. Biomaterials 33, 504-514. doi:10.1016/j.biomaterials. 2011.09.073

Belayev, L., Khoutorova, L., Zhao, K. L., Davidoff, A. W., Moore, A. F., and Cramer, S. C. (2009). A novel neurotrophic therapeutic strategy for experimental stroke. Brain Res. 1280, 117-123. doi:10.1016/j.brainres.2009.05.030

Beom, J., Kim, W., Han, T. R., Seo, K.-S., and Oh, B.-M. (2015). Concurrent use of granulocyte-colony stimulating factor with repetitive transcranial magnetic stimulation did not enhance recovery of function in the early subacute stroke in rats. Neurol. Sci. 36, 771-777. doi:10.1007/s10072-014-2046-4

Bergström, T., Holmqvist, K., Tararuk, T., Johansson, S., and ForsbergNilsson, K. (2014). Developmentally regulated collagen/integrin interactions confer adhesive properties to early postnatal neural stem cells. Biochim. Biophys. Acta 1840, 2526-2532. doi:10.1016/j.bbagen.2014.01.021

Besancon, E., Guo, S., Lok, J., Tymianski, M., and Lo, E. H. (2008). Beyond NMDA and AMPA glutamate receptors: emerging mechanisms for ionic imbalance and cell death in stroke. Trends Pharmacol. Sci. 29, 268-275. doi:10.1016/ j.tips.2008.02.003

Bhattarai, N., Gunn, J., and Zhang, M. (2010). Chitosan-based hydrogels for controlled, localized drug delivery. Adv. Drug Deliv. Rev. 62, 83-99. doi:10.1016/ j.addr.2009.07.019

Bible, E., Chau, D. Y., Alexander, M. R., Price, J., Shakesheff, K. M., and Modo, M. (2009). The support of neural stem cells transplanted into stroke-induced brain cavities by PLGA particles. Biomaterials 30, 2985-2994. doi:10.1016/ j.biomaterials.2009.02.012

Bible, E., Qutachi, O., Chau, D. Y. S., Alexander, M. R., Shakesheff, K. M., and Modo, M. (2012). Neo-vascularization of the stroke cavity by implantation of human neural stem cells on VEGF-releasing PLGA microparticles. Biomaterials 33, 7435-7446. doi:10.1016/j.biomaterials.2012.06.085

Biran, R., Martin, D. C., and Tresco, P. A. (2005). Neuronal cell loss accompanies the brain tissue response to chronically implanted silicon microelectrode arrays. Exp. Neurol. 195, 115-126. doi:10.1016/j.expneurol.2005.04.020

Bithell, A., and Williams, B. P. (2005). Neural stem cells and cell replacement therapy: making the right cells. Clin. Sci. 108, 13-22. doi:10.1042/CS20040276

Bjugstad, K. B., Redmond, D. E. Jr., Lampe, K. J., Kern, D. S., Sladek, J. R. Jr., and Mahoney, M. J. (2008). Biocompatibility of PEG-based hydrogels in primate brain. Cell Transplant. 17, 409-415. doi:10.3727/096368908784423292

Bliss, T. M., Andres, R. H., and Steinberg, G. K. (2010). Optimizing the success of cell transplantation therapy for stroke. Neurobiol. Dis. 37, 275-283. doi:10.1016/ j.nbd.2009.10.003

Bosworth, L. A., Turner, L.-A., and Cartmell, S. H. (2013). State of the art composites comprising electrospun fibres coupled with hydrogels: a review. Nanomedicine 9, 322-335. doi:10.1016/j.nano.2012.10.008

Brouns, R., and De Deyn, P. P. (2009). The complexity of neurobiological processes in acute ischemic stroke. Clin. Neurol. Neurosurg. 111, 483-495. doi:10.1016/j. clineuro.2009.04.001

Brown, C. E., Aminoltejari, K., Erb, H., Winship, I. R., and Murphy, T. H. (2009). In vivo voltage-sensitive dye imaging in adult mice reveals that somatosensory maps lost to stroke are replaced over weeks by new structural and functional circuits with prolonged modes of activation within both the Peri-infarct zone and distant sites. J. Neurosci. 29, 1719-1734. doi:10.1523/JNEUROSCI.424908.2009

Brudno, Y., Ennett-Shepard, A. B., Chen, R. R., Aizenberg, M., and Mooney, D. J. (2013). Enhancing microvascular formation and vessel maturation through temporal control over multiple pro-angiogenic and pro-maturation factors. Biomaterials 34, 9201-9209. doi:10.1016/j.biomaterials.2013.08.007

Buchli, A. D., and Schwab, M. E. (2005). Inhibition of Nogo: a key strategy to increase regeneration, plasticity and functional recovery of the lesioned central nervous system. Ann. Med. 37, 556-567. doi:10.1080/07853890500407520
Cai, L., Dewi, R. E., and Heilshorn, S. C. (2015). Injectable hydrogels with in situ double network formation enhance retention of transplanted stem cells. Adv. Funct. Mater. 25, 1344-1351. doi:10.1002/adfm.201570060

Caicco,M.J.,Cooke, M.J., Wang, Y., Tuladhar, A., Morshead,C.M., andShoichet,M.S. (2013). A hydrogel composite system for sustained epi-cortical delivery of Cyclosporin A to the brain for treatment of stroke. J. Control Release 166, 197-202. doi:10.1016/j.jconrel.2013.01.002

Capila, I., and Linhardt, R. J. (2002). Heparin-protein interactions. Angew. Chem. Int. Ed. Engl. 41, 391-412. doi:10.1002/1521-3773(20020201)41:3<390::AIDANIE390>3.0.CO;2-B

Carlson, A. L., Bennett, N. K., Francis, N. L., Halikere, A., Clarke, S., Moore, J. C., et al. (2016). Generation and transplantation of reprogrammed human neurons in the brain using 3D microtopographic scaffolds. Nat. Commun. 7, 10862. doi:10.1038/ncomms10862

Carmichael, S. T., Archibeque, I., Luke, L., Nolan, T., Momiy, J., and Li, S. (2005). Growth-associated gene expression after stroke: evidence for a growth-promoting region in peri-infarct cortex. Exp. Neurol. 193, 291-311. doi:10.1016/ j.expneurol.2005.01.004

Chao, T. I., Xiang, S., Chen, C.-S., Chin, W.-C., Nelson, A. J., Wang, C., et al. (2009). Carbon nanotubes promote neuron differentiation from human embryonic stem cells. Biochem. Biophys. Res. Commun. 384, 426-430. doi:10.1016/ j.bbrc.2009.04.157

Chen, J., Li, Y., Katakowski, M., Chen, X., Wang, L., Lu, D., et al. (2003). Intravenous bone marrow stronal cell therapy reduces apoptosis and promotes endogenous cell proliferation after stroke in female rat. J. Neurosci. Res. 73, 778-786. doi:10.1002/jnr.10691

Chen, K.-L., Eberli, D., Yoo, J. J., and Atala, A. (2010a). Bioengineered corporal tissue for structural and functional restoration of the penis. Proc. Natl. Acad. Sci. U.S.A. 107, 3346-3350. doi:10.1073/pnas.0909367106

Chen, T. T., Luque, A., Lee, S., Anderson, S. M., Segura, T., and Iruela-Arispe, M. L. (2010b). Anchorage of VEGF to the extracellular matrix conveys differential signaling responses to endothelial cells. J. Cell Biol. 188, 595-609. doi:10.1083/ jcb.200906044

Chen, Q., Zhou, L., and Shine, H. D. (2006). Expression of neurotrophin-3 promotes axonal plasticity in the acute but not chronic injured spinal cord. J. Neurotrauma 23, 1254-1260. doi:10.1089/neu.2006.23.1254

Cheng, T.-Y., Chen, M.-H., Chang, W.-H., Huang, M.-Y., and Wang, T.-W. (2013). Neural stem cells encapsulated in a functionalized self-assembling peptide hydrogel for brain tissue engineering. Biomaterials 34, 2005-2016. doi:10.1016/j.biomaterials.2012.11.043

Cheng, Y., Xi, G., Jin, H., Keep, R. F., Feng, J., and Hua, Y. (2014). Thrombin-induced cerebral hemorrhage: role of protease-activated receptor-1. Transl Stroke Res. 5, 472-475. doi:10.1007/s12975-013-0288-8

Chiasson, B. J., Tropepe, V., Morshead, C. M., and van der Kooy, D. (1999). Adult mammalian forebrain ependymal and subependymal cells demonstrate proliferative potential, but only subependymal cells have neural stem cell characteristics. J. Neurosci. 19, 4462-4471.

Christ, A. F., Franze, K., Gautier, H., Moshayedi, P., Fawcett, J., Franklin, R. J. M., et al. (2010). Mechanical difference between white and gray matter in the rat cerebellum measured by scanning force microscopy. J. Biomech. 43, 2986-2992. doi:10.1016/j.jbiomech.2010.07.002

Christopherson, G. T., Song, H., and Mao, H.-Q. (2009). The influence of fiber diameter of electrospun substrates on neural stem cell differentiation and proliferation. Biomaterials 30, 556-564. doi:10.1016/j.biomaterials.2008.10.004

Clarkson, A. N., Overman, J. J.,Zhong, S., Mueller, R., Lynch, G., and Carmichael, S.T. (2011). AMPA receptor-induced local brain-derived neurotrophic factor signaling mediates motor recovery after stroke. J. Neurosci. 31, 3766-3775. doi:10.1523/JNEUROSCI.5780-10.2011

Clarkson, A. N., Parker, K., Nilsson, M., Walker, F. R., and Gowing, E. K. (2015). Combined ampakine and BDNF treatments enhance poststroke functional recovery in aged mice via AKT-CREB signaling. J. Cereb. Blood Flow Metab. 35, 1272-1279. doi:10.1038/jcbfm.2015.33

Clegg, L. W., and Mac Gabhann, F. (2015). Site-specific phosphorylation of VEGFR2 is mediated by receptor trafficking: insights from a computational model. PLoS Comput. Biol. 11:e1004158. doi:10.1371/journal.pcbi.1004158

Cohen-Sela, E., Teitlboim, S., Chorny, M., Koroukhov, N., Danenberg, H. D., Gao, J., et al. (2009). Single and double emulsion manufacturing techniques of an amphiphilic drug in PLGA nanoparticles: formulations of mithramycin and bioactivity. J. Pharm. Sci. 98, 1452-1462. doi:10.1002/jps.21527 
Cook, D. J., Nguyen, C., Chun, H. N., Llorente, L., Chiu, I., Machnicki, A. S., et al. (2017). Hydrogel-delivered brain-derived neurotrophic factor promotes tissue repair and recovery after stroke. J. Cereb. Blood Flow Metab. 37, 1030-1045. doi:10.1177/0271678X16649964

Cooke, M. J., Wang, Y., Morshead, C. M., and Shoichet, M. S. (2011). Controlled epi-cortical delivery of epidermal growth factor for the stimulation of endogenous neural stem cell proliferation in stroke-injured brain. Biomaterials 32, 5688-5697. doi:10.1016/j.biomaterials.2011.04.032

Cooke, M. J., Zahir, T., Phillips, S. R., Shah, D. S. H., Athey, D., Lakey, J. H., et al. (2010). Neural differentiation regulated by biomimetic surfaces presenting motifs of extracellular matrix proteins. J. Biomed. Mater. Res. 93A, 824-832. doi:10.1002/jbm.a.32585

Cooper, C. A., Brown, K. K., Meletis, C. D., and Zabriskie, N. (2008). Inflammation and hyaluronic acid. Alter. Complementary Ther. 14, 78-84. doi:10.1089/ act.2008.14201

Cramer, S. C., Fitzpatrick, C., Warren, M., Hill, M. D., Brown, D., Whitaker, L., et al. (2010). The beta-hCG plus erythropoietin in acute stroke (BETAS) study A 3-center, single-dose, open-label, noncontrolled, phase IIa safety trial. Stroke 41, 927-931. doi:10.1161/STROKEAHA.109.574343

Dailey, T., Eve, D. J., Tajiri, N., Lau, T., Mosley, Y., Loveren, H., et al. (2013). "Different sources of stem cells for transplantation therapy in stroke," in CellBased Therapies in Stroke, eds J. Jolkkonen and P. Walczak (Vienna: Springer), 29-46.

Dancause, N., Barbay, S., Frost, S. B., Plautz, E. J., Chen, D. F., Zoubina, E. V., et al. (2005). Extensive cortical rewiring after brain injury. J. Neurosci. 25, 10167-10179. doi:10.1523/JNEUROSCI.3256-05.2005

Davoust, C., Plas, B., Béduer, A., Demain, B., Salabert, A.-S., Sol, J.-C., et al. (2017). Regenerative potential of primary adult human neural stem cells on micropatterned bioimplants boosts motor recovery. Curr. Stem Cell Res. Ther. 8, 38. doi:10.1186/s13287-017-0702-3

de Los Ríos la Rosa, F., Khoury, J., Kissela, B. M., Flaherty, M. L., Alwell, K., Moomaw, C. J., et al. (2012). Eligibility for intravenous recombinant tissue-type plasminogen activator within a population the effect of the european cooperative acute stroke study (ECASS) III trial. Stroke 43, 1591-1595. doi:10.1161/ STROKEAHA.111.645986

De Waele, J., Reekmans, K., Daans, J., Goossens, H., Berneman, Z., and Ponsaerts, P. (2015). 3D culture of murine neural stem cells on decellularized mouse brain sections. Biomaterials 41, 122-131. doi:10.1016/j.biomaterials.2014.11.025

Delplace, V., Obermeyer, J., and Shoichet, M. S. (2016). Local affinity release. ACS Nano 10, 6433-6436. doi:10.1021/acsnano.6b04308

Dimyan, M. A., and Cohen, L. G. (2011). Neuroplasticity in the context of motor rehabilitation after stroke. Nat. Rev. Neurol. 7, 76-85. doi:10.1038/ nrneurol.2010.200

Doyle, K. P., Simon, R. P., and Stenzel-Poore, M. P. (2008). Mechanisms of ischemic brain damage. Neuropharmacology 55, 310-318. doi:10.1016/j.neuropharm. 2008.01.005

Drury, J. L., and Mooney, D. J. (2003). Hydrogels for tissue engineering: scaffold design variables and applications. Biomaterials 24, 4337-4351. doi:10.1016/ S0142-9612(03)00340-5

Duggan, P. S., Siegel, A. W., Blass, D. M., Bok, H., Coyle, J. T., Faden, R., et al. (2009). Unintended changes in cognition, mood, and behavior arising from cell-based interventions for neurological conditions: ethical challenges. Am. J. Bioeth. 9, 31-36. doi:10.1080/15265160902788645

Duricki,D.A.,Hutson,T.H.,Kathe,C.,Soleman,S.,Gonzalez-Carter,D.,Petruska,J. C., et al. (2016). Delayed intramuscular human neurotrophin-3 improves recovery in adult and elderly rats after stroke. Brain 139, 259-275. doi:10.1093/brain/ awv341

Dziewczapolski, G., Lie, D. C., Ray, J., Gage, F. H., and Shults, C. W. (2003). Survival and differentiation of adult rat-derived neural progenitor cells transplanted to the striatum of hemiparkinsonian rats. Exp. Neurol. 183, 653-664. doi:10.1016/ S0014-4886(03)00212-7

Ehrbar, M., Rizzi, S. C., Hlushchuk, R., Djonov, V., Zisch, A. H., Hubbell, J. A., et al. (2007). Enzymatic formation of modular cell-instructive fibrin analogs for tissue engineering. Biomaterials 28, 3856-3866. doi:10.1016/j.biomaterials. 2007.03.027

Elkin, B. S., Azeloglu, E. U., Costa, K. D., and Morrison, B. I. (2007). Mechanical heterogeneity of the rat hippocampus measured by atomic force microscope indentation. J. Neurotrauma 24, 812-822. doi:10.1089/neu.2006.0169
Elliott Donaghue, I., Tator, C. H., and Shoichet, M. S. (2015). Sustained delivery of bioactive neurotrophin-3 to the injured spinal cord. Biomater. Sci. 3, 65-72. doi:10.1039/c4bm00311j

Elliott Donaghue, I., Tator, C. H., and Shoichet, M. S. (2016). Local delivery of neurotrophin-3 and anti-NogoA promotes repair after spinal cord injury. Tissue Eng. A 22, 733-741. doi:10.1089/ten.TEA.2015.0471

Emerich, D. F., Silva, E., Ali, O., Mooney, D., Bell, W., Yu, S.-J., et al. (2010). Injectable VEGF hydrogels produce near complete neurological and anatomical protection following cerebral ischemia in rats. Cell Transplant. 19, 1063-1071. doi:10.3727/096368910X498278

Erlandsson,A.,Lin,C.-H.A., Yu,F., andMorshead,C.M.(2011).Immunosuppression promotes endogenous neural stem and progenitor cell migration and tissue regeneration after ischemic injury. Exp. Neurol. 230, 48-57. doi:10.1016/ j.expneurol.2010.05.018

Fawcett, J. W., and Asher, R. A. (1999). The glial scar and central nervous system repair. Brain Res. Bull. 49, 377-391. doi:10.1016/S0361-9230(99)00072-6

Fischl, B., and Dale, A. M. (2000). Measuring the thickness of the human cerebral cortex from magnetic resonance images. Proc. Natl. Acad. Sci. U.S.A. 97, 11050-11055. doi:10.1073/pnas.200033797

Fisher, S. A., Anandakumaran, P. N., Owen, S. C., and Shoichet, M. S. (2015). Tuning the microenvironment: click-crosslinked hyaluronic acid-based hydrogels provide a platform for studying breast cancer cell invasion. Adv. Funct. Mater. 25, 7163-7172. doi:10.1002/adfm.201502778

Fon, D., Zhou, K., Ercole, F., Fehr, F., Marchesan, S., Minter, M. R., et al. (2014). Nanofibrous scaffolds releasing a small molecule BDNF-mimetic for the re-direction of endogenous neuroblast migration in the brain. Biomaterials 35, 2692-2712. doi:10.1016/j.biomaterials.2013.12.016

Forrester, J. V., and Wilkinson, P. C. (1981). Inhibition of leukocyte locomotion by hyaluronic acid. J. Cell. Sci. 48, 315-331.

Freudenberg, U., Hermann, A., Welzel, P. B., Stirl, K., Schwarz, S. C., Grimmer, M., et al. (2009). A star-PEG-heparin hydrogel platform to aid cell replacement therapies for neurodegenerative diseases. Biomaterials 30, 5049-5060. doi:10.1016/j.biomaterials.2009.06.002

Fricker-Gates, R. A., Shin, J. J., Tai, C. C., Catapano, L. A., and Macklis, J. D. (2002). Late-stage immature neocortical neurons reconstruct interhemispheric connections and form synaptic contacts with increased efficiency in adult mouse cortex undergoing targeted neurodegeneration. J. Neurosci. 22, 4045-4056.

Führmann, T., Tam, R. Y., Ballarin, B., Coles, B., Elliott Donaghue, I., van der Kooy, D., et al. (2016). Injectable hydrogel promotes early survival of induced pluripotent stem cell-derived oligodendrocytes and attenuates longterm teratoma formation in a spinal cord injury model. Biomaterials 83, 23-36. doi:10.1016/ j.biomaterials.2015.12.032

García-Alías, G., Barkhuysen, S., Buckle, M., and Fawcett, J. W. (2009). Chondroitinase $\mathrm{ABC}$ treatment opens a window of opportunity for task-specific rehabilitation. Nat. Neurosci. 12, 1145-1151. doi:10.1038/nn.2377

Gardin, C., Piattelli, A., and Zavan, B. (2016). Graphene in regenerative medicine: focus on stem cells and neuronal differentiation. Trends Biotechnol. 34, 435-437. doi:10.1016/j.tibtech.2016.01.006

George, P. M., Bliss, T. M., Hua, T., Lee, A., Oh, B., Levinson, A., et al. (2017). Electrical preconditioning of stem cells with a conductive polymer scaffold enhances stroke recovery. Biomaterials 142, 31-40. doi:10.1016/j.biomaterials. 2017.07.020

Ghuman, H., Massensini, A. R., Donnelly, J., Kim, S.-M., Medberry, C. J., Badylak, S. F., et al. (2016). ECM hydrogel for the treatment of stroke: characterization of the host cell infiltrate. Biomaterials 91, 166-181. doi:10.1016/ j.biomaterials.2016.03.014

Gomi, M., Takagi, Y., Morizane, A., Doi, D., Nishimura, M., Miyamoto, S., et al. (2012). Functional ecovery of the murine brain ischemia model using human induced pluripotent stem cell-derived telecephalic progenitors. Brain Res. 1459, 52-60. doi:10.1016/j.brainres.2012.03.049

Guan, J., Tong, W., Ding, W., Du, S., Xiao, Z., Han, Q., et al. (2012). Neuronal regeneration and protection by collagen-binding BDNF in the rat middle cerebral artery occlusion model. Biomaterials 33, 1386-1395. doi:10.1016/ j.biomaterials.2011.10.073

Guerra-Crespo, M., De la Herran-Arita, A. K., Boronat-Garcia, A., Maya-Espinosa, G., Garcia-Montes, J. R., Fallon, J. H., et al. (2012). "Neural stem cells: exogenous and endogenous promising therapies for stroke," in Neural Stem Cells and Therapy, (London: InTech), 297-342. 
Guo, F., Han, X., Zhang, J., Zhao, X., Lou, J., Chen, H., et al. (2014a). Repetitive transcranial magnetic stimulation promotes neural stem cell proliferation via the regulation of MiR-25 in a rat model of focal cerebral ischemia. PLoS ONE 9, e109267. doi:10.1371/journal.pone.0109267.g004

Guo, Z., Zhang, L., Wu, Z., Chen, Y., Wang, F., and Chen, G. (2014b). In vivo direct reprogramming of reactive glial cells into functional neurons after brain injury and in an Alzheimer's disease model. Cell Stem Cell 14, 188-202. doi:10.1016/ j.stem.2013.12.001

Han, F. Y., Thurecht, K. J., Whittaker, A. K., and Smith, M. T. (2016). Bioerodable PLGA-based microparticles for producing sustained-release drug formulations and strategies for improving drug loading. Front. Pharmacol. 7:185. doi:10.3389/ fphar.2016.00185

Heiss, W.-D. (2012). The ischemic penumbra: how does tissue injury evolve? Ann. N. Y. Acad. Sci. 1268, 26-34. doi:10.1111/j.1749-6632.2012.06668.x

Heng, B. C., Hsu, S. H., Cowan, C. M., Liu, A., Tai, J., Chan, Y., et al. (2009). Transcatheter injection-induced changes in human bone marrow-derived mesenchymal stem cells. Cell Transplant. 18, 1111-1121. doi:10.3727/096368 909X12483162197006

Heo, C., Yoo, J., Lee, S., Jo, A., Jung, S., Yoo, H., et al. (2011). The control of neural cell-to-cell interactions through non-contact electrical field stimulation using graphene electrodes. Biomaterials 32, 19-27. doi:10.1016/ j.biomaterials.2010.08.095

Hersel, U., Dahmen, C., and Kessler, H. (2003). RGD modified polymers: biomaterials for stimulated cell adhesion and beyond. Biomaterials 24, 4385-4415. doi:10.1016/S0142-9612(03)00343-0

Hettiaratchi, M. H., Miller, T., Temenoff, J. S., Guldberg, R. E., and McDevitt, T. C. (2014). Heparin microparticle effects on presentation and bioactivity of bone morphogenetic protein-2. Biomaterials 35, 7228-7238. doi:10.1016/ j.biomaterials.2014.05.011

Hicks, A. U., Lappalainen, R. S., Narkilahti, S., Suuronen, R., Corbett, D., Sivenius, J., et al. (2009). Transplantation of human embryonic stem cell-derived neural precursor cells and enriched environment after cortical stroke in rats: cell survival and functional recovery. Eur. J. Neurosci. 29, 562-574. doi:10.1111/ j.1460-9568.2008.06599.x

Hiscox,L.V., Johnson, C.L., Barnhill,E., McGarry,M.D.J.,Huston,J.,van Beek,E.J. R., et al. (2016). Magnetic resonance elastography (MRE) of the human brain: technique, findings and clinical applications. Phys. Med. Biol. 61, R401-R437. doi:10.1088/0031-9155/61/24/R401

Hoffman, A. S. (2012). Hydrogels for biomedical applications. Adv. Drug Deliv. Rev. 64(Suppl.), 18-23. doi:10.1016/j.addr.2012.09.010

Horie, N., Pereira, M. P., Niizuma, K., Sun, G., Keren-Gill, H., Encarnacion, A., et al. (2011). Transplanted stem cell-secreted vascular endothelial growth factor effects poststroke recovery, inflammation, and vascular repair. Stem Cells 29, 274-285. doi:10.1002/stem.584

Horne, M. K., Nisbet, D. R., Forsythe, J. S., and Parish, C. L. (2010). Threedimensional nanofibrous scaffolds incorporating immobilized BDNF promote proliferation and differentiation of cortical neural stem cells. Stem Cells Dev. 19, 843-852. doi:10.1089/scd.2009.0158

Hossmann, K.-A. (2012). The two pathophysiologies of focal brain ischemia: implications for translational stroke research. J. Cereb. Blood. Flow. Metab. 32, 1310-1316. doi:10.1038/jcbfm.2011.186

Hou, S., Xu, Q., Tian, W., Cui, F., Cai, Q., Ma, J., et al. (2005). The repair of brain lesion by implantation of hyaluronic acid hydrogels modified with laminin. J. Neurosci. Methods 148, 60-70. doi:10.1016/j.jneumeth.2005.04.016

Hu, W., Qiu, B., Guan, W., Wang, Q., Wang, M., Li, W., et al. (2015). Direct conversion of normal and Alzheimer's disease human fibroblasts into neuronal cells by small molecules. Cell Stem Cell 17, 204-212. doi:10.1016/j.stem.2015.07.006

Hunt, J., Cheng, A., Hoyles, A., Jervis, E., and Morshead, C. M. (2010). Cyclosporin A has direct effects on adult neural precursor cells. J. Neurosci. 30, 2888-2896. doi:10.1523/JNEUROSCI.5991-09.2010

Hunt, J., and Morshead, C. (2010). Cyclosporin A enhances cell survival in neural precursor populations in the adult central nervous system. Mol. Cell. Pharmacol. 2, 81-88. doi:10.4255/mcpharmacol.10.11

Ikeda, T., Iwai, M., Hayashi, T. K., Nagano, I., Shogi, M., Ikenoue, T., et al. (2005). Limited differentiation to neurons and astroglia from neural stem cells in the cortex and triatum after ischemia/hypoxia in the neonatal rat brain. Am. J. Obstet. Gynecol. 193, 849-856. doi:10.1016/j.ajog.2005.01.029

Ishibashi, S., Sakaguchi, M., Kuroiwa, T., Yamasaki, M., Kanemura, Y., Shizuko, I., et al. (2004). Human neural stem/progenitor cells, expanded in long-term neurosphere culture, promote functional recovery after focal ischemia in Mongolian gerbils. J. Neurosci. Res. 78, 215-223. doi:10.1002/jnr.20246

Iwasa, S. N., Babona-Pilipos, R., and Morshead, C. M. (2017). Environmental factors that influence stem cell migration: an "electric field". Stem Cells Int. 2017, 4276927. doi:10.1155/2017/4276927

Jen, A. C., Wake, M. C., and Mikos, A. G. (1996). Hydrogels for cell immobilization. Biotechnol. Bioeng. 50, 357-364. doi:10.1002/(SICI)1097-0290 (19960520)50:4<357::AID-BIT2>3.0.CO;2-K

Jin, K., Mao, X., Xie, L., Galvan, V., Lai, B., Wang, Y., et al. (2010). Transplantation of human neural precursor cells in Matrigel scaffolding improves outcome from focal cerebral ischemia after delayed postischemic treatment in rats. J. Cereb. Blood Flow Metab. 30, 534-544. doi:10.1038/jcbfm.2009.219

Jin, K., Sun, Y., Xie, L., Mao, X. O., Childs, J., Peel, A., et al. (2005). Comparison of ischemia-directed migration of neural precursor cells after intrastriatal, intraventricular, or intravenous transplantation in the rat. Neurobiol. Dis. 18, 366-374. doi:10.1016/j.nbd.2004.10.010

Jin, K., Xie, L., Mao, X., Greenberg, M. B., Moore, A., Peng, B., et al. (2011a). Effect of human neural precursor cell transplantation on endogenous neurogenesis after focal cerebral ischemia in the rat. Brain Res. 1374, 56-62. doi:10.1016/ j.brainres.2010.12.037

Jin, Y.-C., Kim, S.-W., Cheng, F., Shin, J.-H., Park, J.-K., Lee, S., et al. (2011b). The effect of biodegradable gelatin microspheres on the neuroprotective effects of high mobility group box $1 \mathrm{~A}$ box in the postischemic brain. Biomaterials 32, 899-908. doi:10.1016/j.biomaterials.2010.09.054

Jongpaiboonkit, L., King, W. J., and Murphy, W. L. (2008). Screening for 3D environments that support human mesenchymal stem cell viability using hydrogel arrays. Tissue Eng. Part A 15, 343-353. doi:10.1089/ten.tea.2008.0096

Ju, R., Wen, Y., Gou, R., Wang, Y., and Xu, Q. (2014). The experimental therapy on brain ischemia by improvement of local angiogenesis with tissue engineering in the mouse. Cell Transplant. 23(Suppl. 1), S83-S95. doi:10.3727/096368914X684998

Kandalam, S., Sindji, L., Delcroix, G. J. R., Violet, F., Garric, X., André, E. M., et al. (2017). Pharmacologically active microcarriers delivering BDNF within a hydrogel: novel strategy for human bone marrow-derived stem cells neural/ neuronal differentiation guidance and therapeutic secretome enhancement. Acta Biomater. 49, 167-180. doi:10.1016/j.actbio.2016.11.030

Kanekar, S. G., Zacharia, T., and Roller, R. (2012). Imaging of stroke: part 2, pathophysiology at the molecular and cellular levels and corresponding imaging changes. AJR Am. J. Roentgenol. 198, 63-74. doi:10.2214/AJR.10.7312

Kawai, H., Yamashita, T., Oha, Y., Deguchi, K., Nagotani, S., Zhang, X., et al. (2010). Tridermal tumorigenesis of induced pluripotent stem cells transplanted in ischemic brain. J. Cereb. Blood Flow Metab. 30, 1487-1493. doi:10.1038/jcbfm.2010.32

Kelly, S., Bliss, T. M., Shah, A. K., Sun, G. H., Ma, M., Foo, W. C., et al. (2004). Transplanted human fetal neural stem cells survive, migrate, and differentiate in ischemic rat cerebral cortex. Proc. Natl. Acad. Sci. U.S.A. 101, 11839-11844. doi:10.1073/pnas.0404474101

Kernie, S. G., and Parent, J. M. (2010). Forebrain neurogenesis after focal Ischemic and traumatic brain injury. Neurobiol. Dis. 37, 267-274. doi:10.1016/ j.nbd.2009.11.002

Khaing, Z. Z., and Seidlits, S. K. (2015). Hyaluronic acid and neural stem cells: implications for biomaterial design. J. Mater. Chem. B 3, 7850-7866. doi:10.1039/C5TB00974J

Khedr, E. M., Etraby, A. E., Hemeda, M., Nasef, A. M., and Razek, A. A. E. (2010). Long-term effect of repetitive transcranial magnetic stimulation on motor function recovery after acute ischemic stroke. Acta Neurol. Scand. 121, 30-37. doi:10.1111/j.1600-0404.2009.01195.x

Kolb, B., Morshead, C., Gonzalez, C., Kim, M., Gregg, C., Shingo, T., et al. (2007). Growth factor-stimulated generation of new cortical tissue and functional recovery after stroke damage to the motor cortex of rats. J. Cereb. Blood Flow Metab. 27, 983-997. doi:10.1038/sj.jcbfm.9600402

Koshy, S. T., Zhang, D. K. Y., Grolman, J. M., Stafford, A. G., and Mooney, D. J. (2018). Injectable nanocomposite cryogels for versatile protein drug delivery. Acta Biomater. 65, 36-43. doi:10.1016/j.actbio.2017.11.024

Kremer, K. L., Smith, A.E.,Sandeman, L., Inglis, J. M., Ridding, M.C., and Koblar, S. A. (2016). Transcranial magnetic stimulation of human adult stem cells in the mammalian brain. Front. Neural Circuits 10:17. doi:10.3389/fncir.2016.00017

Krueger, M., Haertig, W., Reichenbach, A., Bechmann, I., and Michalski, D. (2013). Blood-brain barrier breakdown after embolic stroke in rats occurs without ultrastructural evidence for disrupting tight junctions. PLOS ONE 8:e56419. doi:10.1371/journal.pone.0056419 
Kruse, S. A., Rose, G. H., Glaser, K. J., Manduca, A., Felmlee, J. P., Jack, C. R. J., et al. (2008). Magnetic resonance elastography of the brain. Neuroimage 39, 231-237. doi:10.1016/j.neuroimage.2007.08.030

Kumar, M. N. V. R., Bakowsky, U., and Lehr, C. M. (2004). Preparation and characterization of cationic PLGA nanospheres as DNA carriers. Biomaterials 25, 1771-1777. doi:10.1016/j.biomaterials.2003.08.069

Kumar, N., Langer, R. S., and Domb, A. J. (2002). Polyanhydrides: an overview. $A d v$. Drug Deliv. Rev. 54, 889-910. doi:10.1016/S0169-409X(02)00050-9

Kuroiwa, T., Ting, P., Martinez, H., and Klatzo, I. (1985). The biphasic opening of the blood-brain-barrier to proteins following temporary middle cerebral-artery occlusion. Acta Neuropathol. 68, 122-129. doi:10.1007/BF00688633

Lam, J., Carmichael, S. T., Lowry, W. E., and Segura, T. (2015). Hydrogel design of experiments methodology to optimize hydrogel for iPSC-NPC culture. Adv. Healthc. Mater. 4, 534-539. doi:10.1002/adhm.201400410

Lam, J., Lowry, W. E., Carmichael, S. T., and Segura, T. (2014). Delivery of iPSNPCs to the stroke cavity within a hyaluronic acid matrix promotes the differentiation of transplanted cells. Adv. Funct. Mater. 24, 7053-7062. doi:10.1002/ adfm.201401483

Lampe, K. J., Kern, D. S., Mahoney, M. J., and Bjugstad, K. B. (2011). The administration of BDNF and GDNF to the brain via PLGA microparticles patterned within a degradable PEG-based hydrogel: protein distribution and the glial response. J. Biomed. Mater. Res. 96, 595-607. doi:10.1002/jbm.a.33011

Langer, R. (1990). New methods of drug delivery. Science 249, 1527-1533. doi:10.1126/science.2218494

Lau, L. W., Cua, R., Keough, M. B., Haylock-Jacobs, S., and Yong, V. W. (2013). Pathophysiology of the brain extracellular matrix: a new target for remyelination. Nat. Rev. Neurosci. 14, 722-729. doi:10.1038/nrn3550

Lee, I.-H., Huang, S.-S., Chuang, C.-Y., Liao, K.-H., Chang, L.-H., Chuang, C.-C., et al. (2017). Delayed epidural transplantation of human induced pluripotent stem cell-derived neural progenitors enhances functional recovery after stroke. Sci. Rep. 7, 1943. doi:10.1038/s41598-017-02137-w

Lee, K. Y., and Mooney, D. J. (2001). Hydrogels for tissue engineering. Chem. Rev. 101, 1869-1879. doi:10.1021/cr000108x

Li, L., Harms, K. M., Ventura, P. B., Lagace, D. C., Eisch, A. J., and Cunningham, L. A. (2010). Focal cerebral ischemia induces a multi lineage cytogenic response from adult subventricular zone that is predominantly gliogenic. Glia 58, 1610-1619. doi:10.1002/glia.21033

Li, X., Kozielski, K., Cheng, Y.-H., Liu, H., Zamboni, C. G., Green, J., et al. (2016). Nanoparticle-mediated conversion of primary human astrocytes into neurons and oligodendrocytes. Biomater. Sci. 4, 1100-1112. doi:10.1039/c6bm00140h

Li, X., Tzeng, S. Y., Zamboni, C. G., Koliatsos, V. E., Ming, G.-L., Green, J. J., et al. (2017). Enhancing oligodendrocyte differentiation by transient transcription activation via DNA nanoparticle-mediated transfection. Acta Biomater. 54, 249-258. doi:10.1016/j.actbio.2017.03.032

Li, X., Zuo, X., Jing, J., Ma, Y., Wang, J., Liu, D., et al. (2015). Small-molecule-driven direct reprogramming of mouse fibroblasts into functional neurons. Cell Stem Cell 17, 195-203. doi:10.1016/j.stem.2015.06.003

Li, Y., Liu, M., Yan, Y., and Yang, S.-T. (2014). Neural differentiation from pluripotent stem cells: the role of natural and synthetic extracellular matrix. World J. Stem Cells 6, 11-23. doi:10.4252/wjsc.v6.i1.11

Lin, Y.-H., Chang, C.-H., Wu, Y.-S., Hsu, Y.-M., Chiou, S.-F., and Chen, Y.-J. (2009). Development of pH-responsive chitosan/heparin nanoparticles for stomach-specific anti-Helicobacter pylori therapy. Biomaterials 30, 3332-3342. doi:10.1016/j.biomaterials.2009.02.036

Lindvall, O., and Kokaia, Z. (2010). Stem cells in human neurodegenerative disorders - time for clinical translation? J. Clin. Invest. 120, 29-40. doi:10.1172/ JCI40543

Lindvall, O., and Kokaia, Z. (2011). Stem cell research in stroke: how far from the clinic? Stroke 42, 2369-2375. doi:10.1161/STROKEAHA.110.599654

Liu, B. P., Cafferty, W. B. J., Budel, S. O., and Strittmatter, S. M. (2006). Extracellular regulators of axonal growth in the adult central nervous system. Philos. Trans. $R$ Soc. Lond. B Biol. Sci. 361, 1593-1610. doi:10.1098/rstb.2006.1891

Liu, Z., Li, Y., Cui, Y., Roberts, C., Lu, M., Wilhelmsson, U., et al. (2014). Beneficial effects of gfap/vimentin reactive astrocytes for axonal remodeling and motor behavioral recovery in mice after stroke. Glia 62, 2022-2033. doi:10.1002/ glia.22723

Lu, A., Tang, Y., Ran, R., Clark, J. F., Aronow, B. J., and Sharp, F. R. (2003). Genomics of the periinfarction cortex after focal cerebral ischemia. J. Cereb. Blood Flow Metab. 23, 786-810. doi:10.1097/01.WCB.0000062340.80057.06
Luft, A. R., Waller, S., Forrester, L., Smith, G. V., Whitall, J., Macko, R. F., et al. (2004). Lesion location alters brain activation in chronically impaired stroke survivors. Neuroimage 21, 924-935. doi:10.1016/j.neuroimage.2003.10.026

Ma, J., Tian, W.-M., Hou, S.-P., Xu, Q. Y., Spector, M., and Cui, F. Z. (2007). An experimental test of stroke recovery by implanting a hyaluronic acid hydrogel carrying a Nogo receptor antibody in a rat model. Biomed. Mater. 2, 233-240. doi:10.1088/1748-6041/2/4/005

Ma, W., Fitzgerald, W., Liu, Q.-Y., O’shaughnessy, T. J., Maric, D., Lin, H. J., et al. (2004). CNS stem and progenitor cell differentiation into functional neuronal circuits in three-dimensional collagen gels. Exp. Neurol. 190, 276-288. doi:10.1016/j.expneurol.2003.10.016

Ma, W., Tavakoli, T., Derby, E., Serebryakova, Y., Rao, M. S., and Mattson, M. P. (2008). Cell-extracellular matrix interactions regulate neural differentiation of human embryonic stem cells. BMC Dev. Biol. 8:90. doi:10.1186/1471-213X-8-90

Mahoney, M. J., and Anseth, K. S. (2007). Contrasting effects of collagen and bFGF-2 on neural cell function in degradable synthetic PEG hydrogels. J. Biomed. Mater. Res. 81A, 269-278. doi:10.1002/jbm.a.30970

Massensini, A. R., Ghuman, H., Saldin, L. T., Medberry, C. J., Keane, T. J., Nicholls, F. J., et al. (2015). Concentration-dependent rheological properties of ECM hydrogel for intracerebral delivery to a stroke cavity. Acta Biomater. 27, 116-130. doi:10.1016/j.actbio.2015.08.040

Massey, J. M., Hubscher, C. H., Wagoner, M. R., Decker, J. A., Amps, J., Silver, J. et al. (2006). Chondroitinase ABC digestion of the perineuronal net promotes functional collateral sprouting in the cuneate nucleus after cervical spinal cord injury. J. Neurosci. 26, 4406-4414. doi:10.1523/JNEUROSCI.5467-05.2006

Mead, P. A., Safdieh, J. E., Nizza, P., Tuma, S., and Sepkowitz, K. A. (2014). Ommaya reservoir infections: a 16-year retrospective analysis. J. Infect. 68, 225-230. doi:10.1016/j.jinf.2013.11.014

Medberry, C. J., Crapo, P. M., Siu, B. F., Carruthers, C. A., Wolf, M. T., Nagarkar, S. P., et al. (2013). Hydrogels derived from central nervous system extracellular matrix. Biomaterials 34, 1033-1040. doi:10.1016/j.biomaterials.2012.10.062

Mehta, A. M., Sonabend, A. M., and Bruce, J. N. (2017). Convection-enhanced delivery. Neurotherapeutics 14, 358-371. doi:10.1007/s13311-017-0520-4

Menaa, F., Abdelghani, A., and Menaa, B. (2015). Graphene nanomaterials as biocompatible and conductive scaffolds for stem cells: impact for tissue engineering and regenerative medicine. J. Tissue Eng. Regen. Med. 9, 1321-1338. doi:10.1002/term.1910

Meretoja, A., Keshtkaran, M., Tatlisumak, T., Donnan, G. A., and Churilov, L. (2017). Endovascular therapy for ischemic stroke: save a minute-save a week. Neurology 88, 2123-2127. doi:10.1212/WNL.0000000000003981

Milner, R., and Campbell, I. L. (2002). The integrin family of cell adhesion molecules has multiple functions within the CNS. J. Neurosci. Res. 69, 286-291. doi:10.1002/jnr.10321

Minger, S. L., Ekonomou, A., Carta, E. M., Chinoy, A., Perry, R. H., and Ballard, C. G. (2007). Endogenous neurogenesis in the human brain following cerebral infarction. Regen. Med. 2, 69-74. doi:10.2217/17460751.2.1.69

Minnerup, J., Sutherland, B. A., BUCHAN, A. M., and Kleinschnitz, C. (2012) Neuroprotection for stroke: current status and future perspectives. Int. J. Mol. Sci. 13, 11753-11772. doi:10.3390/ijms130911753

Misra, A., Ganesh, S., Shahiwala, A., and Shah, S. P. (2003). Drug delivery to the central nervous system: a review. J. Pharm. Pharm. Sci. 6, 252-273.

Mo, L., Yang, Z., Zhang, A., and Li, X. (2010). The repair of the injured adult rat hippocampus with NT-3-chitosan carriers. Biomaterials 31, 2184-2192. doi:10.1016/j.biomaterials.2009.11.078

Modo, M., Stroemer, R. P., Tang, E., Patel, S., and Hodges, H. (2002). Effects of implantation site of stem cell grafts on behavioral recovery from stroke damage. Stroke 33, 2270-2278. doi:10.1161/01.STR.0000027693.50675.C5

Moeendarbary, E., Weber, I. P., Sheridan, G. K., Koser, D. E., Soleman, S., Haenzi, B., et al. (2017). The soft mechanical signature of glial scars in the central nervous system. Nat. Commun. 8, 14787. doi:10.1038/ncomms14787

Mohammadi-Samani, S., and Taghipour, B. (2015). PLGA micro and nanoparticles in delivery of peptides and proteins; problems and approaches. Pharm. Dev. Technol. 20, 385-393. doi:10.3109/10837450.2014.882940

Morshead, C. M., Reynolds, B. A., Craig, C. G., McBurney, M. W., Staines, W. A., Morassutti, D., et al. (1994). Neural stem cells in the adult mammalian forebrain: a relatively quiescent subpopulation of subependymal cells. Neuron 13, 1071-1082. doi:10.1016/0896-6273(94)90046-9

Moshayedi, P., Nih, L. R., Llorente, I. L., Berg, A. R., Cinkornpumin, J., Lowry, W. E., et al. (2016). Systematic optimization of an engineered hydrogel allows for 
selective control of human neural stem cell survival and differentiation after transplantation in the stroke brain. Biomaterials 105, 145-155. doi:10.1016/ j.biomaterials.2016.07.028

Mozaffarian, D., Benjamin, E. J., Go, A. S., Arnett, D. K., Blaha, M. J., Cushman, M., et al. (2016). Heart disease and stroke statistics-2016 update: a report from the American Heart Association. Circulation 133, e38-e360. doi:10.1161/ CIR.0000000000000366

Müller, H. D., Hanumanthiah, K. M., Diederich, K., Schwab, S., Schäbitz, W.-R., and Sommer, C. (2008). Brain-derived neurotrophic factor but not forced arm use improves long-term outcome after photothrombotic stroke and transiently upregulates binding densities of excitatory glutamate receptors in the rat brain. Stroke 39, 1012-1021. doi:10.1161/STROKEAHA.107.495069

Murphy, T. H., and Corbett, D. (2009). Plasticity during stroke recovery: from synapse to behaviour. Nat. Rev. Neurosci. 10, 861-872. doi:10.1038/nrn2735

Nair, L. S., and Laurencin, C. T. (2007). Biodegradable polymers as biomaterials. Prog. Polym. Sci. 32, 762-798. doi:10.1016/j.progpolymsci.2007.05.017

Nakagomi, N., Nakagomi, T., Kubo, S., Nakano-Doi, A., Saino, O., Takata, M., et al. (2009). Endothelial cells support survival, proliferation, and neuonal differentiation of transplanted adult ischemia-induced neural stem/progenitor cells after cerebral infarction. Stem Cells 27, 2185-2195. doi:10.1002/stem.161

Nakaguchi, K., Jinnou, H., Kaneko, N., Sawada, M., Hikita, T., Saitoh, S., et al. (2012). Growth factors released from gelatin hydrogel microspheres increase new neurons in the adult mouse brain. Stem Cells Int. 2012, 915160. doi:10.1155/2012/915160

Nakatomi, H., Kuriu, T., Okabe, S., Yamamoto, S.-I., Hatano, O., Kawahara, N., et al. (2002). Regeneration of hippocampal pyramidal neurons after ischemic brain injury by recruitment of endogenous neural progenitors. Cell 110, 429-441. doi:10.1016/S0092-8674(02)00862-0

Niclis, J. C., Turner, C., Durnall, J., McDougal, S., Kauhausen, J. A., Leaw, B., et al. (2017). Long-distance axonal growth and protracted functional maturation of neurons derived from human induced pluripotent stem cells after intracerebral transplantation. Stem Cells Transl. Med. 6, 1547-1556. doi:10.1002/ sctm.16-0198

Nih, L. R., Carmichael, S. T., and Segura, T. (2016). Hydrogels for brain repair after stroke: an emerging treatment option. Curr. Opin. Biotechnol. 40, 155-163. doi:10.1016/j.copbio.2016.04.021

Nih, L. R., Sideris, E., Carmichael, S. T., and Segura, T. (2017). Injection of microporous annealing particle (MAP) hydrogels in the stroke cavity reduces gliosis and inflammation and promotes NPC migration to the lesion. Adv. Mater. Weinheim 29. doi:10.1002/adma.201606471

Nimmo, C. M., and Shoichet, M. S. (2011). Regenerative biomaterials that "Click": simple, aqueous-based protocols for hydrogel synthesis, surface immobilization, and 3D patterning. Bioconjug. Chem. 22, 2199-2209. doi:10.1021/bc200281k

Nisbet, D. R., Rodda, A. E., Horne, M. K., Forsythe, J. S., and Finkelstein, D. I. (2009). Neurite infiltration and cellular response to electrospun polycaprolactone scaffolds implanted into the brain. Biomaterials 30, 4573-4580. doi:10.1016/j. biomaterials.2009.05.011

Niu, W., Zang, T., Zou, Y., Fang, S., Smith, D. K., Bachoo, R., et al. (2013). In vivo reprogramming of astrocytes to neuroblasts in the adult brain. Nat. Cell Biol. 15, 1164-1175. doi:10.1038/ncb2843

Nudo, R. J., Wise, B. M., SiFuentes, F., and Milliken, G. W. (1996). Neural substrates for the effects of rehabilitative training on motor recovery after ischemic infarct. Science 272, 1791-1794. doi:10.1126/science.272.5269.1791

O'Collins, V. E., Macleod, M. R., Donnan, G. A., Horky, L. L., van der Worp, B. H., and Howells, D. W. (2006). 1,026 experimental treatments in acute stroke. Ann. Neurol. 59, 467-477. doi:10.1002/ana.20741

Oki, K., Tatarishvili, J., Wood, J., Koch, P., Wattananit, S., Mine, Y., et al. (2012). Human-induced pluripotent stem cells form functional neurons and improve recovery after grafting in stroke-damaged brain. Stem Cells 30, 1120-1133. doi:10.1002/stem.1104

Pakulska, M. M., Donaghue, I. E., Obermeyer,J. M., Tuladhar, A., McLaughlin, C. K., Shendruk, T. N., et al. (2016a). Encapsulation-free controlled release: electrostatic adsorption eliminates the need for protein encapsulation in PLGA nanoparticles. Sci. Adv. 2, e1600519-e1600519. doi:10.1126/sciadv.1600519

Pakulska, M. M., Miersch, S., and Shoichet, M. S. (2016b). Designer protein delivery: from natural to engineered affinity-controlled release systems. Science 351, aac4750. doi:10.1126/science.aac4750

Pakulska, M. M., Tator, C. H., and Shoichet, M. S. (2017). Local delivery of chondroitinase $\mathrm{ABC}$ with or without stromal cell-derived factor $1 \alpha$ promotes functional repair in the injured rat spinal cord. Biomaterials 134, 13-21. doi:10.1016/j.biomaterials.2017.04.016

Pakulska, M. M., Vulic, K., and Shoichet, M. S. (2013). Affinity-based release of chondroitinase $\mathrm{ABC}$ from a modified methylcellulose hydrogel. J. Control. Release 171, 11-16. doi:10.1016/j.jconrel.2013.06.029

Pan, L., North, H. A., Sahni, V., Jeong, S. J., McGuire, T. L., Berns, E. J., et al. (2014). $\beta 1$-integrin and integrin linked kinase regulate astrocytic differentiation of neural stem cells. PLoS ONE 9:e104335. doi:10.1371/journal.pone.0104335

Pardridge, W. M. (2003). Blood-brain barrier drug targeting: the future of brain drug development. Mol. Interv. 3, 90-105-51. doi:10.1124/mi.3.2.90

Pardridge, W. M. (2011). Drug transport in brain via the cerebrospinal fluid. Fluids Barriers CNS 8, 7. doi:10.1186/2045-8118-8-7

Pardridge, W. M. (2012). Drug transport across the blood-brain barrier. J. Cereb. Blood Flow Metab. 32, 1959-1972. doi:10.1038/jcbfm.2012.126

Parent, J. M., Vexler, Z. S., Gong, C., Derugin, N., and Ferriero, D. M. (2002). Rat forebrain neurogenesis and striatal neuron replacement after focal stroke. Ann. Neurol. 52, 802-813. doi:10.1002/ana.10393

Park, K. I., Teng, Y. D., and Snyder, E. Y. (2002). The injured brain itneracts reciprocally with neural stem cells supported by scaffolds to reconstitute lost tissue. Nat. Biotechnol. 20, 1111-1117. doi:10.1038/nbt751

Patel, T. D., Kramer, I., Kucera, J., Niederkofler, V., Jessell, T. M., Arber, S., et al. (2003). Peripheral NT3 signaling is required for ETS protein expression and central patterning of proprioceptive sensory afferents. Neuron 38, 403-416. doi:10.1016/S0896-6273(03)00261-7

Payne, S. L., Anandakumaran, P. N., Varga, B. V., Morshead, C. M., Nagy, A., and Shoichet, M. S. (2018). In vitro maturation of human iPSC-derived neuroepithelial cells influences transplant survival in the stroke-injured rat brain. Tissue Eng. Part A 24, 351-360. doi:10.1089/ten.tea.2016.0515

Pekarek, K. J. K., Jacob, J. S. J., and Mathiowitz, E. E. (1994). Double-walled polymer microspheres for controlled drug release. Nature 367, 258-260. doi:10.1038/ $367258 \mathrm{a} 0$

Pencea, V., Bingaman, K. D., Freedman, L. J., and Luskin, M. B. (2001). Neurogenesis in the subventricular zone and rostral migratory stream of the neonatal and adult primate forebrain. Exp. Neurol. 172, 1-16. doi:10.1006/exnr.2001.7768

Pires, F., Ferreira, Q., Rodrigues, C. A. V., Morgado, J., and Ferreira, F. C. (2015). Neural stem cell differentiation by electrical stimulation using a cross-linked PEDOT substrate: expanding the use of biocompatible conjugated conductive polymers for neural tissue engineering. Biochim. Biophys. Acta 1850, 1158-1168. doi:10.1016/j.bbagen.2015.01.020

Ploughman, M., Windle, V., MacLellan, C. L., White, N., Doré, J. J., and Corbett, D. (2009). Brain-derived neurotrophic factor contributes to recovery of skilled reaching after focal ischemia in rats. Stroke 40, 1490-1495. doi:10.1161/ STROKEAHA.108.531806

Pollauf, E. J., Kim, K. K., and Pack, D. W. (2005). Small-molecule release from poly(D,L-lactide)/poly(D,L-lactide-co-glycolide) composite microparticles. J. Pharm. Sci. 94, 2013-2022. doi:10.1002/jps.20408

Purcell, B. P., Lobb, D., Charati, M. B., Dorsey, S. M., Wade, R. J., Zellars, K. N., et al. (2014). Injectable and bioresponsive hydrogels for on-demand matrix metalloproteinase inhibition. Nat. Mater. 13, 653-661. doi:10.1038/ nmat3922

Quittet, M.-S., Touzani, O., Sindji, L., Cayon, J., Fillesoye, F., Toutain, J., et al. (2015). Effects of mesenchymal stem cell therapy, in association with pharmacologically active microcarriers releasing VEGF, in an ischaemic stroke model in the rat. Acta Biomater. 15, 77-88. doi:10.1016/j.actbio.2014.12.017

Rajah, G. B., and Ding, Y. (2017). Experimental neuroprotection in ischemic stroke: a concise review. Neurosurg. Focus 42, E2. doi:10.3171/2017.1.FOCUS16497

Richardson, T. P., Peters, M. C., Ennett, A. B., and Mooney, D. J. (2001). Polymeric system for dual growth factor delivery. Nat. Biotechnol. 19, 1029-1034. doi:10.1038/nbt1101-1029

Rosenblum, S., Smith, T. N., Wang, N., Chua, J. Y., Westbroek, E., Wang, K., et al. (2015). BDNF pretreatment of human embryonic-derived neural stem cells improves cell survival and functional recovery after transplantation in hypoxic-ischemic stroke. Cell Transplant. 24, 2449-2461. doi:10.3727/096368 914X679354

Rossetti, T., Nicholls, F., and Modo, M. (2016). Intracerebral cell implantation: preparation and characterization of cell suspensions. Cell Transplant. 25, 645-664. doi:10.3727/096368915X690350

Ruhrberg, C., Gerhardt, H., Golding, M., Watson, R., Ioannidou, S., Fujisawa, H., et al. (2002). Spatially restricted patterning cues provided by heparin-binding 
VEGF-A control blood vessel branching morphogenesis. Genes Dev. 16, 2684-2698. doi:10.1101/gad.242002

Rundhaug, J. E. (2005). Matrix metalloproteinases and angiogenesis. J. Cell. Mol. Med. 9, 267-285. doi:10.1111/j.1582-4934.2005.tb00355.x

Sachewsky, N., Hunt, J., Cooke, M. J., Azimi, A., Zarin, T., Miu, C., et al. (2014). Cyclosporin A enhances neural precursor cell survival in mice through a calcineurin-independent pathway. Dis. Model Mech. 7, 953-961. doi:10.1242/ dmm. 014480

Sakiyama-Elbert, S. E. (2014). Incorporation of heparin into biomaterials. Acta Biomater. 10, 1581-1587. doi:10.1016/j.actbio.2013.08.045

Saver, J. L., Albers, G. W., Dunn, B., Johnston, K. C., Fisher, M., and Consortium, S. V. (2009). Stroke therapy academic industry roundtable (STAIR) recommendations for extended window acute stroke therapy trials. Stroke 40, 2594-2600. doi:10.1161/STROKEAHA.109.552554

Savitz, S. I., Chopp, M., Deans, R., Carmichael, S. T., Phinney, D., and Wechsler, L. (2011). Stem cell therapy as an emerging paradigm for stroke (STEPS) II. Stroke 42, 825-829. doi:10.1161/STROKEAHA.110.601914

Saxena, S., and Caroni, P. (2011). Selective neuronal vulnerability in neurodegenerative diseases: from stressor thresholds to degeneration. Neuron 71, 35-48. doi:10.1016/j.neuron.2011.06.031

Schabitz, W. R., Schwab, S., Spranger, M., and Hacke, W. (1997). Intraventricular brain-derived neurotrophic factor reduces infarct size after focal cerebral ischemia in rats. J. Cereb. Blood Flow Metab. 17, 500-506. doi:10.1097/00004647-199705000-00003

Schnell, E., Klinkhammer, K., Balzer, S., Brook, G., Klee, D., Dalton, P., et al. (2007). Guidance of glial cell migration and axonal growth on electrospun nanofibers of poly-epsilon-caprolactone and a collagen/poly-epsilon-caprolactone blend. Biomaterials 28, 3012-3025. doi:10.1016/j.biomaterials.2007.03.009

Schwab, M. E., and Strittmatter, S. M. (2014). Nogo limits neural plasticity and recovery from injury. Curr. Opin. Neurobiol. 27, 53-60. doi:10.1016/ j.conb.2014.02.011

Seghier, M. L., Ramsden, S., Lim, L., Leff, A. P., and Price, C. J. (2014). Gradual lesion expansion and brain shrinkage years after stroke. Stroke 45, 877-879. doi:10.1161/STROKEAHA.113.003587

Seidlits, S. K., Gower, R. M., Shepard, J. A., and Shea, L. D. (2013). Hydrogels for lentiviral gene delivery. Expert Opin. Drug Deliv. 10, 499-509. doi:10.1517/17 425247.2013.764864

Seidlits, S. K., Khaing, Z. Z., Petersen, R. R., Nickels, J. D., Vanscoy, J. E., Shear, J. B., et al. (2010). The effects of hyaluronic acid hydrogels with tunable mechanical properties on neural progenitor cell differentiation. Biomaterials 31, 3930-3940. doi:10.1016/j.biomaterials.2010.01.125

Shin, S., and Shea, L. D. (2010). Lentivirus immobilization to nanoparticles for enhanced and localized delivery from hydrogels. Mol. Ther. 18, 700-706. doi:10.1038/mt.2009.300

Smith, E. J., Stroemer, R. P., Gorenkova, N., Nakajima, M., Crum, W. R., Tang, E., et al. (2012). Implantation site and lesion topology determine efficacy of a human neural stem cell line in a rat model of chronic stroke. Stem Cells 30, 785-796. doi:10.1002/stem.1024

Soleman, S., Yip, P. K., Duricki, D. A., and Moon, L. D. F. (2012). Delayed treatment with chondroitinase $\mathrm{ABC}$ promotes sensorimotor recovery and plasticity after stroke in aged rats. Brain 135, 1210-1223. doi:10.1093/brain/aws027

Somaa, F. A., Wang, T.-Y., Niclis, J. C., Bruggeman, K. F., Kauhausen, J. A., Guo, H., et al. (2017). Peptide-based scaffolds support human cortical progenitor graft integration to reduce atrophy and promote functional repair in a model of stroke. Cell Rep. 20, 1964-1977. doi:10.1016/j.celrep.2017.07.069

Soppimath, K. S., Aminabhavi, T. M., Kulkarni, A. R., and Rudzinski, W. E. (2001). Biodegradable polymeric nanoparticles as drug delivery devices. J. Control Release 70, 1-20. doi:10.1016/S0168-3659(00)00339-4

Spencer, K. C., Sy, J. C., Ramadi, K. B., Graybiel, A. M., Langer, R., and Cima, M. J. (2017). Characterization of mechanically matched hydrogel coatings to improve the biocompatibility of neural implants. Sci. Rep. 7, 1952. doi:10.1038/ s41598-017-02107-2

Stabenfeldt, S. E., García, A. J., and LaPlaca, M. C. (2006). Thermoreversible laminin-functionalized hydrogel for neural tissue engineering. J. Biomed. Mater. Res. 77, 718-725. doi:10.1002/jbm.a.30638

Stabenfeldt, S. E., Gautam, M., Garcia, A. J., and LaPlaca, M. C. (2010). Biomimetic microenvironment modumales neural stem cell survival, migration, and differentiation. Tissue Eng. A 16, 3747-3758. doi:10.1089/ten.tea.2009.0837
Stemer, A., and Lyden, P. (2010). Evolution of the thrombolytic treatment window for acute ischemic stroke. Curr. Neurol. Neurosci. Rep. 10, 29-33. doi:10.1007/ s11910-009-0076-8

Stroke Therapy Academic Industry Roundtable(STAIR). (1999). Recommendations for standards regarding preclinical neuroprotective and restorative drug development. Stroke 30, 2752-2758. doi:10.1161/01.STR.30.12.2752

Struzyna, L. A., Wolf, J. A., Mietus, C. J., Adewole, D. O., Chen, H. I., Smith, D. H., et al. (2015). Rebuilding brain circuitry with living micro-tissue engineered neural networks. Tissue Eng. Part A 21, 2744-2756. doi:10.1089/ten.TEA.2014.0557

Sutherland, B. A., Minnerup, J., Balami, J. S., Arba, F., Buchan, A. M., and Kleinschnitz, C. (2012). Neuroprotection for ischaemic stroke: translation from the bench to the bedside. Int. J. Stroke 7, 407-418. doi:10.1111/j. 1747-4949.2012.00770.x

Syková, E., and Nicholson, C. (2008). Diffusion in brain extracellular space. Physiol. Rev. 88, 1277-1340. doi:10.1152/physrev.00027.2007

Takeuchi, N., Chuma, T., Matsuo, Y., Watanabe, I., and Ikoma, K. (2005). Repetitive transcranial magnetic stimulation of contralesional primary motor cortex improves hand function after stroke. Stroke 36, 2681-2686. doi:10.1161/01. STR.0000189658.51972.34

Taluja, A., Youn, Y. S., and Bae, Y. H. (2007). Novel approaches in microparticulate PLGA delivery systems encapsulating proteins. J. Mater. Chem. 17, 4002-4017. doi:10.1039/b706939a

Tam, R. Y., Cooke, M. J., and Shoichet, M. (2012). Covalently modified hydrogel blend of hyaluronan-methyl cellulose with peptides and growth factors influences neural stem/progenitor cell fate. J. Mater. Chem. 22, 19402-19411. doi:10.1039/c2jm33680d

Tarus, D., Hamard, L., Caraguel, F., Wion, D., Szarpak-Jankowska, A., van der Sanden, B., et al. (2016). Design of hyaluronic acid hydrogels to promote neurite outgrowth in three dimensions. ACS Appl. Mater. Interfaces 8, 25051-25059. doi:10.1021/acsami.6b06446

Tate, C. C., Shear, D. A., Tate, M. C., Archer, D. R., Stein, D. G., and LaPlaca, M. C. (2009). Laminin and fibronectin scaffolds enhance neural stem cell transplantation into the injured brain. J. Tissue Eng. Regen. Med. 3, 208-217. doi:10.1002/ term. 154

Thoenen, H. (1995). Neurotrophins and neuronal plasticity. Science 270, 593-598. doi:10.1126/science.270.5236.593

Thorne, R. G., Lakkaraju, A., Rodriguez-Boulan, E., and Nicholson, C. (2008). In vivo diffusion of lactoferrin in brain extracellular space is regulated by interactions with heparan sulfate. Proc. Natl. Acad. Sci. U.S.A. 105, 8416-8421. doi:10.1073/pnas.0711345105

Tombari, D., Loubinoux, I., Pariente, J., Gerdelat, A., Albucher, J.-F., Tardy, J., et al. (2004). A longitudinal fMRI study: in recovering and then in clinically stable sub-cortical stroke patients. Neuroimage 23, 827-839. doi:10.1016/ j.neuroimage.2004.07.058

Tornero, D., Tsupykov, O., Granmo, M., Rodriguez, C., Grønning-Hansen, M., Thelin, J., et al. (2017). Synaptic inputs from stroke-injured brain to grafted human stem cell-derived neurons activated by sensory stimuli. Brain 140, 692-706. doi:10.1093/brain/aww347

Tornero, D., Wattananit, S., Grønning Madsen, M., Koch, P., Wood, J., Tatarishvili, J., et al. (2013). Human induced pluripotent stem cell-derived cortical neurons integrate in stroke-injured cortex and improve functional recovery. Brain 136, 3561-3577. doi:10.1093/brain/awt278

Touzani, O., Roussel, S., and MacKenzie, E. T. (2001). The ischaemic penumbra. Curr. Opin. Neurol. 14, 83-88. doi:10.1097/00019052-200102000-00013

Tuladhar, A., Morshead, C. M., and Shoichet, M. S. (2015). Circumventing the bloodbrain barrier: local delivery of cyclosporin A stimulates stem cells in strokeinjured rat brain. J. Control Release 215, 1-11. doi:10.1016/j.jconrel.2015.07.023

Tyler, W. J. (2012). The mechanobiology of brain function. Nat. Rev. Neurosci. 13, 867-878. doi:10.1038/nrn3383

Uemura, M., Refaat, M. M., Shinoyama, M., Hayashi, H., Hashimoto, N., and Takahashi, J. (2010). Matrigel supports survival and neuronal differentiation of grafted embryonic stem cell-derived neural precursor cells. J. Neurosci. Res. 88, 542-551. doi:10.1002/jnr.22223

Vasilevich, A. S., Carlier, A., de Boer, J., and Singh, S. (2017). How not to drown in data: a guide for biomaterial engineers. Trends Biotechnol. 35, 743-755. doi:10.1016/j.tibtech.2017.05.007

Vaysse, L., Beduer, A., Sol, J. C., Vieu, C., and Loubinoux, I. (2015). Micropatterned bioimplant with guided neuronal cells to promote tissue reconstruction and 
improve functional recovery after primary motor cortex insult. Biomaterials 58 , 46-53. doi:10.1016/j.biomaterials.2015.04.019

Velier, J. J., Ellison, J. A., Kikly, K. K., Spera, P. A., Barone, F. C., and Feuerstein, G. Z. (1999). Caspase-8 and caspase-3 are expressed by different populations of cortical neurons undergoing delayed cell death after focal stroke in the rat. J. Neurosci. 19, 5932-5941.

Vulic, K., and Shoichet, M. S. (2014). Affinity-based drug delivery systems for tissue repair and regeneration. Biomacromolecules 15, 3867-3880. doi:10.1021/ bm501084u

Vulic, K. K., and Shoichet, M. S. M. (2012). Tunable growth factor delivery from injectable hydrogels for tissue engineering. J. Am. Chem. Soc. 134, 882-885. doi:10.1021/ja210638x

Vykhodtseva, N., McDannold, N., and Hynynen, K. (2008). Progress and problems in the application of focused ultrasound for blood-brain barrier disruption. Ultrasonics 48, 279-296. doi:10.1016/j.ultras.2008.04.004

Wang, C., Poon, S., Murali, S., Koo, C.-Y., Bell, T. J., Hinkley, S. F., et al. (2014). Engineering a vascular endothelial growth factor 165-binding heparan sulfate for vascular therapy. Biomaterials 35, 6776-6786. doi:10.1016/ j.biomaterials.2014.04.084

Wang, D., and Fawcett, J. (2012). The perineuronal net and the control of CNS plasticity. Cell Tissue Res. 349, 147-160. doi:10.1007/s00441-012-1375-y

Wang, H.-Y., Crupi, D., Liu, J., Stucky, A., Cruciata, G., Di Rocco, A., et al. (2011a). Repetitive transcranial magnetic stimulation enhances BDNF-TrkB signaling in both brain and lymphocyte. J. Neurosci. 31, 11044-11054. doi:10.1523/ JNEUROSCI.2125-11.2011

Wang, Y., Cooke, M. J., Lapitsky, Y., Wylie, R. G., Sachewsky, N., Corbett, D., et al. (2011b). Transport of epidermal growth factor in the stroke-injured brain. J. Control Release 149, 225-235. doi:10.1016/j.jconrel.2010.10.022

Wang, J., Gallagher, D., DeVito, L. M., Cancino, G. I., Tsui, D., He, L., et al. (2012a). Metformin activates an atypical PKC-CBP pathway to promote neurogenesisand enhance spatial memory formation. Stem Cell 11, 23-35. doi:10.1016/ j.stem.2012.03.016

Wang, Y., Cooke, M. J., Morshead, C. M., and Shoichet, M. S. (2012b). Hydrogel delivery of erythropoietin to the brain for endogenous stem cell stimulation after stroke injury. Biomaterials 33, 2681-2692. doi:10.1016/ j.biomaterials.2011.12.031

Wang, Y., Cooke, M. J., Sachewsky, N., Morshead, C. M., and Shoichet, M. S. (2013). Bioengineered sequential growth factor delivery stimulates brain tissue regeneration after stroke. J. Control Release 172, 1-11. doi:10.1016/j.jconrel.2013.07.032

Wei, Y. T., Tian, W. M., Yu, X., Cui, F. Z., Hou, S. P., Xu, Q. Y., et al. (2007). Hyaluronic acid hydrogels with IKVAV peptides for tissue repair and axonal regeneration in an injured rat brain. Biomed. Mater. 2, S142. doi:10.1088/1748-6041/2/3/S11

Wernig, M., Benninger, F., Schmandt, T., Rade, M., Tucker, K. L., Bussow, H., et al. (2004). Functional integration of embryonic stem cell-derived neurons in vivo. J. Neurosci. 24, 5258-5268. doi:10.1523/JNEUROSCI.0428-04.200

Wieloch, T., and Nikolich, K. (2006). Mechanisms of neural plasticity following brain injury. Curr. Opin. Neurobiol. 16, 258-264. doi:10.1016/j.conb.2006. 05.011

Willing, A., and Shahaduzzaman, M. (2013). "Delivery routes for cell therapy in stroke," in Cell-Based Therapies in Stroke, eds J. Jolkkonen and P. Walczak (Vienna: Springer), 15-28.

Wiltrout, C., Lang, B., Yan, Y., Dempsey, R. J., and Vemuganti, R. (2007). Repairing brain after stroke: a review on post-ischemic neurogenesis. Neurochem. Int. 50, 1028-1041. doi:10.1016/j.neuint.2007.04.011

Winhuisen, L., Thiel, A., Schumacher, B., Kessler, J., Rudolf, J., Haupt, W. F., et al. (2005). Role of the contralateral inferior frontal gyrus in recovery of language function in poststroke aphasia - a combined repetitive transcranial magnetic stimulation and positron emission tomography study. Stroke 36, 1759-1763. doi:10.1161/01.STR.0000174487.81126.ef

Winship, I. R., and Murphy, T. H. (2008). In vivo calcium imaging reveals functional rewiring of single somatosensory neurons after stroke. J. Neurosci. 28, 6592-6606. doi:10.1523/JNEUROSCI.0622-08.2008
Winstein, C. J., Stein, J., Arena, R., Bates, B., Cherney, L. R., Cramer, S. C., et al. (2016). Guidelines for adult stroke rehabilitation and recovery: a guideline for healthcare professionals from the American Heart Association/American Stroke Association. Stroke 47, E98-E169. doi:10.1161/STR.0000000000000098

Winter, C. C., Katiyar, K. S., Hernandez, N. S., Song, Y. J., Struzyna, L. A., Harris, J. P., et al. (2016). Transplantable living scaffolds comprised of micro-tissue engineered aligned astrocyte networks to facilitate central nervous system regeneration. Acta Biomater. 38, 44-58. doi:10.1016/j.actbio.2016.04.021

Wojcik-Stanaszek, L., Gregor, A., and Zalewska, T. (2011). Regulation of neurogenesis by extracellular matrix and integrins. Acta Neurobiol. Exp. 71, 103-112.

Xing, C., Arai, K., Lo, E. H., and Hommel, M. (2012). Pathophysiologic cascades in ischemic stroke. Int. J. Stroke 7, 378-385. doi:10.1111/j.1747-4949.2012.00839.x

Yamada, M., Tanemura, K., Okada, S., Iwanami, A., Nakamura, M., Mizuno, H., et al. (2007). Electrical stimulation modulates fate determination of differentiating embryonic stem cells. Stem Cells 25, 562-570. doi:10.1634/stemcells.2006-0011

Yamashita, T., Kawai, H., Tian, F., Ohta, Y., and Abe, K. (2011). Tumorigenic development of induced pluripotent stem cells in ischemic mouse brain. Cell Transplant. 20, 883-891. doi:10.3727/096368910X539092

Yamashita, T., Liu, W., Matsumura, Y., Miyagi, R., Zhai, Y., Kusaki, M., et al. (2017). Novel therapeutic transplantation of induced neural stem cells for stroke. Cell Transplant. 26, 461-467. doi:10.3727/096368916X692988

Yamashita, T., Ninomiya, M., Hernández Acosta, P., García-Verdugo, J. M., Sunabori, T., Sakaguchi, M., et al. (2006). Subventricular zone-derived neuroblasts migrate and differentiate into mature neurons in the post-stroke adult striatum. J. Neurosci. 26, 6627-6636. doi:10.1523/JNEUROSCI.0149-06.2006

Yasuda, Y., Tateishi, N., Shimoda, T., Satoh, S., Ogitani, E., and Fujita, S. (2004). Relationship between S100 beta and GFAP expression in astrocytes during infarction and glial scar formation after mild transient ischemia. Brain Res. 1021, 20-31. doi:10.1016/j.brainres.2004.06.015

Zhang, H., Hayashi, T., Tsuru, K., Deguchi, K., Nagahara, M., Hayakawa, S., et al. (2007). Vascular endothelial growth factor promotes brain tissue regeneration with a novel biomaterial polydimethylsiloxane-tetraethoxysilane. Brain Res. 1132, 29-35. doi:10.1016/j.brainres.2006.09.117

Zhang, L., Yin, J.-C., Yeh, H., Ma, N.-X., Lee, G., Chen, X. A., et al. (2015). Small molecules efficiently reprogram human astroglial cells into functional neurons. Cell Stem Cell 17, 735-747. doi:10.1016/j.stem.2015.09.012

Zhang, P., Li, J., Liu, Y., Chen, X., Lu, H., Kang, Q., et al. (2011). Human embryonic neural stem cell transplantation increases subventricular zone cell proliferation and promotes peri-infarct angiogenesis after focal cerebral ischemia. Neuropathology 31, 384-391. doi:10.1111/j.1440-1789.2010.01182.x

Zhang, Z. G., and Chopp, M. (2009). Neurorestorative therapies for stroke: underlying mechanisms and translation to the clinic. Lancet Neurol. 8, 491-500. doi:10.1016/S1474-4422(09)70061-4

Zhong, J., Chan, A., Morad, L., Kornblum, H. I., Guoping, F., and Carmichael, S. T. (2010). Hydrogel matrix to support stem cell survival after brain transplantation in stroke. Neurorehabil. Neural Repair 24, 636-644. doi:10.1177/ 1545968310361958

Zhou, T., Hong, G., Fu, T.-M., Yang, X., Schuhmann, T. G., Viveros, R. D., et al. (2017). Syringe-injectable mesh electronics integrate seamlessly with minimal chronic immune response in the brain. Proc. Natl. Acad. Sci. U.S.A. 114, 5894-5899. doi:10.1073/pnas.1705509114

Conflict of Interest Statement: The authors declare that the research was conducted in the absence of any commercial or financial relationships that could be construed as a potential conflict of interest.

Copyright ( 2018 Tuladhar, Payne and Shoichet. This is an open-access article distributed under the terms of the Creative Commons Attribution License (CC $B Y)$. The use, distribution or reproduction in other forums is permitted, provided the original author(s) and the copyright owner are credited and that the original publication in this journal is cited, in accordance with accepted academic practice. No use, distribution or reproduction is permitted which does not comply with these terms. 